\title{
A LEX MERCATORIA E AS NOVAS TENDÊNCIAS DE CODIFICAÇÃO DO DIREITO DO COMÉRCIO INTERNACIONAL
}

\author{
Douglas Alexander Cordeiro
}

\section{RESUMO}

Apesar de citada por muitos autores, a denominada lex mercatoria não encontra um conceito definido na doutrina e diversas são as controvérsias quanto a sua natureza jurídica. Não obstante, observa-se que o comércio internacional, desde a antiguidade, sofre a influência de um conjunto de regras, usos e costumes muito peculiar, criado pelos próprios atores do comércio internacional e por eles aplicado e regulado, atualmente objeto de tentativas de consolidação e codificação por institutos privados, cujo objetivo principal é unificar as "regras do jogo" do comércio internacional.

\section{ABSTRACT}

Although mentioned by many authors, the so-called lex mercatoria is not a defined concept in doctrine and there are several controversies concerning its content. However, one may observe that international trade has the influence of a very peculiar set of rules, practices and customs since the ancient times, created by the actors of international trade, applied and regulated by themselves, which is currently the object of attempts to consolidate and codificate of private institutions, whose main goal is to unify the "game rules" of international trade.

INDICADORES: Lex mercatoria; comércio internacional; codificação

Revista Brasileira de Direito Internacional, Curitiba, v.7, n.7, jan./jun.2008 


\section{INTRODUÇÃO}

O comércio internacional, por seu dinamismo e constante evolução, contribui para o desenvolvimento e renovação do direito desde o seu princípio. A necessidade dos comerciantes internacionais implicou a criação de instrumentos jurídicos como as cambiais, o surgimento dos Bancos e das Bolsas de Valores, do seguro, do crédito documentário e de certas características de alguns tipos de sociedades, como a limitação da responsabilidade dos sócios e a existência da pessoa jurídica de forma autônoma e desvinculada da figura das pessoas físicas que Ihe deram vida. ${ }^{1}$ Concomitantemente a esse desenvolvimento, a atuação do Estado diminuiu, tornando-se relevante a participação das empresas privadas.

Tais fatores, aliados ao desenvolvimento dos meios de comunicação e da superação das fronteiras nacionais pelos comerciantes, implicaram o surgimento de um novo conjunto regras, nascidas da prática comercial e desvinculadas das normas legais dos Estados aos quais pertencem os personagens da relação comercial.

A existência de tal conjunto pode ser observada principalmente após o fim da II Guerra Mundial, quando há um novo movimento comercial em busca de regras e normas mais adequadas às necessidades dos comerciantes, independentemente das regras nacionais existentes.

A doutrina internacional passa, então, a questionar o ponto de vista tradicional segundo o qual a legislação nacional é a mais adequada para a solução de todo e qualquer litígio e vê, então, a necessidade de estabelecer meios de solucioná-los diante do novo panorama do comércio internacional.

Não obstante as diferenças políticas e econômicas existentes entre os sistemas jurídicos mundiais, menciona Goldstaijn que

"uma nova lei mercante se desenvolve rapidamente no âmbito do comércio internacional mundial. É tempo de reconhecer a existência

\footnotetext{
${ }^{1}$ AMARAL, A. C. R. do. Direito do Comércio Internacional: aspectos fundamentais. São Paulo: Aduaneiras, 2004. p. 57.
}

Revista Brasileira de Direito Internacional, Curitiba, v.7, n.7, jan./jun.2008 
de uma lei do comércio autônoma que cresce independente dos sistemas jurídicos nacionais". ${ }^{2}$

Tal lei mercante é também conhecida como lex mercatoria. O vocábulo "nova", utilizado por Goldstaijn e por outros autores, faz referência à Lei Mercante que regia os negócios internacionais desde a antiguidade, cujas características foram também encontradas nesse conjunto de regras desvinculadas de qualquer sistema jurídico estatal que rege o comércio internacional hodierno.

A primeira obra de que se tem conhecimento sobre a lex mercatoria, intitulada "Vel lex mercatoria or the Ancient Law Merchant" é publicada por Gerard Malynes em 1622, segundo o qual

todo homem sabe, que para formas e prescrições, há grandes diversidades entre todas as nações, mas para os costumes observados no curso do tráfico e do comércio, há aquela simpatia, concordância e acordo, o que pode ser dito para ser condição para todas as pessoas, difundida e espalhada pela razão correta, e pelo instinto natural permanente. E esses costumes são propriamente aquelas observações que os comerciantes mantêm entre eles mesmos. E essa Lei dos Comerciantes até então observada em todos os países, em relação ao comércio deveria ser estimada e realizada assim como a Lei das Doze Tábuas foi entre os Romanos. Por esses motivos todas as coisas serão encontradas construídas sobre as fundações da Razão e da Justiça. ${ }^{3}$

\footnotetext{
2 "Notwithstanding the differences in the political, economic and legal system of the world, a new law merchant is rapidly developing in the world of international trade. It is time that recognition be given to the existence of an autonomous commercial law that has grown independent of the national systems of law". GOLDSTAIJN, A. The new law merchant reconsidered. Festschrift Schmitthoff. Frankfurt, 1973. p. 171.

3 "Every man knweth, that for Manners and Prescriptions, there is great diversitie amongth all Nations: but for the Customs observed in the course of trafficke and commerce, there is that sympathy, concordance and agreement, which may bee said to bee of like condition to all people, diffused and spread by right reason, and instinct of nature consisting perpetually. And these customs are properly those observations which merchants maintaine betweene themselves". Id, at 8: " (...) and this Law of Merchants hitherto observed in all countries, ought in regard of commerce, to be esteemed and held to reputation as the Law of Twelve Tables was amongst the Romans. For herein you shall find everything built upon the foundations of Reason and Justice (...)'. MALYNES, G. Consuetudo Vel Lex Mercatoria or The Ancient Law Merchant. London: Adam Islip, 1622. p. 3 apud BERGER, K. P. The Creeping Codification of the Lex Mercatoria. Hague: Kluwer Law International, 1999. p. 1.
}

Revista Brasileira de Direito Internacional, Curitiba, v.7, n.7, jan./jun.2008 
Não há, porém, uma definição clara na doutrina para o fenômeno da lex mercatoria, havendo tantos conceitos possíveis quanto o número de autores que trataram do tema.

Um dos pioneiros a tratar sobre o tema no século XIX, Berthold Goldman, a definia como "um conjunto de princípios e regras costumeiros, espontaneamente referidos ou elaborados no quadro do comércio internacional, sem referencia a um sistema particular ou lei nacional"4.

Heighet, por sua vez, concebia a lex mercatoria como os princípios que são aplicados por juízes ou árbitros como fonte de regras jurídicas, para fundamentar decisões, da mesma maneira como estes aplicariam regras de um verdadeiro sistema jurídico, como a lei nacional do local em que o contrato foi celebrado ou a lei do local onde se realiza a arbitragem. ${ }^{5}$

Já para Rodriguez, a lex mercatoria pode ser definida como um conjunto de regras diferentes na origem e no conteúdo, criada pela comunidade comercial para servir ao comércio internacional. ${ }^{6}$

Para Goldstaijn, a "lei do comércio internacional" pode ser definida como o conjunto de regras que rege as relações comerciais de natureza privada, envolvendo diferentes países. ${ }^{7}$

Strenger ainda a define como "um conjunto de procedimentos que possibilita adequadas soluções para as expectativas do comércio internacional,

\footnotetext{
${ }^{4}$ GOLDMAN, B. Frontières du droit et lex mercatoria. Archives de Philosophie du droit. Paris, $\mathrm{n}$. 09, pg. 179 apud FIORATI, Jete J. A lex mercatoria como ordenamento jurídico autônomo e os Estados em desenvolvimento. Revista de Informação Legislativa. Brasília, ano 41, n. 164, p. 19. out-dez 2004.

5 "What is lex mercatoria? I would take it to mean more or less the following. The principles of the developing transnational or international law merchant, capable of being applied by decisionmakers (judges or arbitrators) as a source of legal rules, in order to give content to decisions, in much the same way that these decisionmakers would apply a real legal system such as the lex fori or the lex loci arbitri'. HEIGHET, Keith. The enigma of the lex mercatoria, In: CARBONNEAU, T. E. (ed.). Lex mercatoria and arbitration: a discussion of the new law merchant. New York: Juris Publications, 1998. p. 101.

6 "The lex mercatoria may be generally defined as the body of rules, different in origin and content, created by the trade community to serve the needs of international trade". RODRIGUEZ, A. M. L. Lex mercatoria. Retsvidenskabeligt Tidsskrift, 2002. p. 47.

7 GOLDSTAIJN, A. The new law merchant reconsidered. Festschrift Schmitthoff. Frankfurt, 1973. p. 171. "The expression the "Law of International Trade" may be defined as the body of rules governing commercial relationships of a private law nature involving different countries".
}

Revista Brasileira de Direito Internacional, Curitiba, v.7, n.7, jan./jun.2008 
sem conexões necessárias com os sistemas nacionais e de forma juridicamente eficaz". ${ }^{8}$

Para Sweet, trata-se de um sistema legal repleto de sua própria lei dos contratos "a-nacional", bem como de um sistema legal formado por Cortes

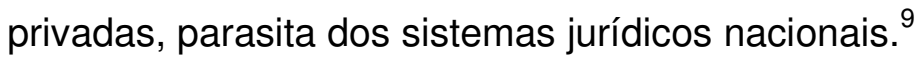

Outros autores trataram ainda sobre o tema, como Clive Schmitthoff, que concebia a lex mercatoria como um conjunto de princípios comuns relacionados aos negócios internacionais presentes em regras uniformes que tem aceitabilidade generalizada ${ }^{10}$ e Langen, que a identificava como as regras do jogo do comércio internacional ${ }^{11}$.

Apesar das divergências na Doutrina sobre a "Teoria da lex mercatoria", sua existência e sua atuação no comércio internacional não são questionadas. As críticas que se fizeram e que ainda se fazem aos defensores da lex mercatoria, versam essencialmente sobre a natureza normativa ou a natureza jurídica da nova Lei Mercante.

O objetivo principal deste trabalho será discorrer sobre o surgimento, a evolução histórica e as atuais características da lex mercatoria, analisando as tendências atuais rumo à codificação do direito do comércio internacional, principalmente após o advento, na década de 90 dos Princípios UNIDROIT sobre os Contratos Comerciais Internacionais (UPICC) e dos Princípios do Direito Europeu dos Contratos.

Assim como na Idade Média, a lex mercatoria atualmente é alvo de um processo de consolidação de usos e costumes do comércio internacional. A conjuntura sócio-econômica hodierna, entretanto, implica uma reflexão mais profunda, qual seja, sobre a possível codificação do direito internacional

\footnotetext{
${ }^{8}$ STRENGER, I. Direito do comércio internacional e lex mercatoria. São Paulo: LTr, 1996. p. 78.

9 "This legal system [lex mercatoria] - replete with its own 'a-national' law of contract and a system of private 'courts'- is parasitic on state authorithy. SWEET, A. S. The new lex mercatoria and transnational governance. Journal of European Public Policy. Londres, 05/08/2006. p. 627.

${ }^{10}$ FIORATI, J. J. A lex mercatoria como ordenamento jurídico autônomo e os Estados em desenvolvimento. Revista de Informação Legislativa. Brasília, ano 41, n. 164, p. 19. out-dez 2004.

11 "The rules of the game of international trade". LANGEN, E. Transnational Commercial Law. Leiden, p.33, 1973. apud STRENGER, I. Direito do Comércio Internacional e lex mercatoria. São Paulo: LTr, 1996. p. 76.
}

Revista Brasileira de Direito Internacional, Curitiba, v.7, n.7, jan./jun.2008 
privado e, em especial, sobre a possível codificação do direito do comércio internacional.

\section{ASPECTOS HISTÓRICOS DA LEX MERCATORIA}

A lex mercatoria não é um fenômeno ou invenção dos doutrinadores do século XX, mas, ao contrário, desenvolve-se desde o surgimento do comércio internacional para atender às necessidades da comunidade mercante.

O seu surgimento, entretanto, é ainda um enigma a ser decifrado pela doutrina. Alguns autores admitem seu início na Itália, em plena Idade Média, enquanto outros crêem que sua existência remonta à época em que os Árabes dominaram o mar mediterrâneo. ${ }^{12}$

A análise da evolução histórica de seu conceito e escopo, entretanto, é fundamental para se compreender o seu estágio atual de desenvolvimento, bem como para embasar as discussões futuras quanto à sua possível codificação.

\subsection{A ANTIGA LEX MERCATORIA}

O uso freqüente do termo "nova" lex mercatoria ou "nova" lei mercante implica a existência de uma "antiga" lei dos mercadores. A sua existência pode ser observada desde a antiguidade, desde o surgimento das primeiras formas de comércio internacional.

Os primeiros registros de comércio "internacional", realizado entre diferentes povos, remetem ao comércio marítimo realizado pelos Fenícios entre o século XV e XIV a. C..

Para Dal Ri Junior, apenas no período das cidades-estado gregas (séc. VIII a VI a. C.) surgem as primeiras "normas" do comércio marítimo, que consolidam os costumes da época e que, ainda hoje, são encontrados nos contratos internacionais:

\footnotetext{
${ }^{12}$ PEREIRA, L. C. R. Costume Internacional: Gênese do Direito Internacional. Rio de Janeiro: Renovar, 2002. p. 286.
}

Revista Brasileira de Direito Internacional, Curitiba, v.7, n.7, jan./jun.2008 
"É neste período [cidades-estado gregas] que surgem também alguns costumes que historicamente se consolidaram como importantes normas de comércio marítimo, até hoje previstas na maioria dos contratos nesta matéria. É o caso da chamada Lei de Rodes posteriormente latinizidada como lex rhodia -, prevendo que, em caso de necessidade de jogar no mar parte da carga de uma embarcação mercantil, evitando assim o naufrágio, o prejuízo seja dividido em partes iguais por todos os estados proprietários das mercadorias que estão sendo transportadas. (...) O mesmo acontece com a regra do nautikon daneion - posteriormente latinizada como nauticum fenus -, prevendo que o comerciante que tivesse contraído um empréstimo para carregar sua embarcação, sendo que em meio à viagem tivesse acontecido um naufrágio, estaria isento do pagamento da dívida. Ao contrário, tendo a viagem marítima obtido sucesso, o comerciante deveria pagar juros que poderiam ir de $30 \%$ a $50 \% .^{13}$

A expansão territorial promovida pela civilização helenística também assinalou uma "evolução econômica unicamente comparável, em magnitude, [apenas] às revoluções comerciais e industriais da Era Moderna" ${ }^{14}$, a qual trouxe consigo o desenvolvimento de um sistema de produção do comércio e das finanças, além da expansão das rotas comerciais marítimas e terrestres em busca de novos mercados, proporcionando acesso a produtos dos mais variados locais pela população.

Em Roma, o jus gentium pode também ser considerado um importante disciplinador do comércio internacional, ao regular as relações econômicas existentes entre estrangeiros e cidadãos romanos. A partir da metade do século III a.C. os romanos passaram a utilizar cortes especiais, sob autoridade do praetor peregrinus, para julgar os casos que envolvessem estrangeiros ao invés de aplicar sua própria lei (ius civile).

Alguns autores mencionam que tais tribunais possuíam um escopo muito próximo ao das atuais cortes arbitrais, pois suas decisões também

\footnotetext{
${ }^{13}$ DAL RI JUNIOR, A. História do Direito Internacional. Florianópolis: Fundação Boiteux, 2004. p. 22.

${ }^{14}$ STRENGER, I. Direito do Comércio Internacional e Lex Mercatoria. São Paulo: LTr, 1996. p. 56.
}

Revista Brasileira de Direito Internacional, Curitiba, v.7, n.7, jan./jun.2008 
criavam uma base (jurisprudência) que posteriormente poderia ser utilizada como referência em outros julgamentos. ${ }^{15}$

Com a desburocratização do ius civile e após a concessão da cidadania romana a todos os habitantes do Império em 212 d. C., com a Constitutio Antoiania, o ius gentium gradativamente perdeu sua importância, caindo em desuso.

A partir do séc. III Roma começa a enfrentar as ameaças Bárbaras e, menciona Strenger ${ }^{16}$, o comércio internacional conhece sua primeira fase de decadência, na qual vive séculos de um período "escuro". O advento da Idade Média, entretanto, é marcado pela luta pela liberdade e pelo desenvolvimento contra as velhas instituições políticas e contra a burocracia das Leis Romanas.

\subsection{A LEX MERCATORIA MEDIEVAL}

A partir do século XI o comércio internacional é revitalizado na Europa, diante de fatores como as Cruzadas, a conquista da Sicília, Sardenha e Córsega, a criação da Liga Hanseática, dentre outros. A sociedade medieval estava isolada após o declínio do Império Romano, as leis, usos e costumes variavam de cidade para cidade e algumas delas, em especial aquelas derivadas do direito canônico, eram empecilhos ao desenvolvimento do comércio. $^{17}$

O comércio, entretanto, ao invés de cessar ou regredir evoluiu e transpôs as fronteiras então existentes, encontrando outras fontes normativas para embasar as relações comerciais além das fronteiras nacionais. As Regras de Oléron, por exemplo, desde 1150 já eram aceitas e utilizadas por um vasto

${ }^{15}$ BADDACK, F. Lex Mercatoria: Scope and Application of the Law Merchant in Arbitration. Tese (LL.M., mode III) - Faculty of Law, University of the Western Cape, Cape Town, South Africa, 2005. p. 6.

${ }^{16}$ STRENGER, I. Direito do Comércio Internacional e Lex Mercatoria. São Paulo: LTr, 1996. p. 57.

${ }_{17}$ BADDACK, F. Lex Mercatoria: Scope and Application of the Law Merchant in Arbitration. Tese (LL.M., mode III) - Faculty of Law, University of the Western Cape, Cape Town, South Africa, 2005. p. 7.

Revista Brasileira de Direito Internacional, Curitiba, v.7, n.7, jan./jun.2008 
número de comerciantes marítimos e utilizada por um grande número de portos marítimos no Mar do Norte e no Oceano Atlântico. ${ }^{18}$

As Leis de Wisby, possivelmente derivadas das Regras de Oléron, que em 1350 regulavam o comércio no mar báltico e as disposições do Consulado do Mar, editadas pela Corte Consular de Barcelona no século XIV para consolidar os costumes do comércio marítimo, são também consideradas manifestações de um direito medieval dos comerciantes. ${ }^{19}$

Aos poucos, o rigor e a burocracia das regras do direito romano foram substituídos pelos usos e costumes dos comerciantes que, ante a falta de um poder político central, uniram-se em grupos de acordo com as atividades exercidas por seus membros.

Tais grupos, denominados corporações de mercadores, possuíam patrimônio próprio constituído através de doações de seus associados. Tinham o objetivo inicial de proteger e dar assistência aos seus membros e, aos poucos, acabaram assimilando também função jurisdicional para resolver os conflitos havidos entre mercadores. A magistratura mercantilista assumia, então, (i) funções políticas (ao defender a honra e dignidade das corporações às quais pertenciam, colaborar com a manutenção da paz, etc.), (ii) funções executivas (observar o cumprimento das disposições estatutárias, leis e usos mercantis) e (iii) funções judiciais (solucionando os conflitos mercantis).

Surge, então, um conjunto de normas direcionadas a um grupo específico de profissionais, lastreado nos usos e costumes de uma classe carente de um direito estatal específico. Tal conjunto não surge de uma atividade legislativa nem da criação de jurisconsultos, como na Roma Antiga, mas sim dos próprios comerciantes em uma tentativa de superar as obsoletas e frágeis normas feudais e romanas, que não mais correspondiam aos seus interesses e ao novo modelo de comércio nacional e internacional então existente.

\footnotetext{
18 RULES OF OLERON, The. Disponível em: $<$ http://www.admiraltylawguide.com/documents/oleron.html> Acesso em 05/08/2008.

${ }^{19}$ AMARAL, A. C. R. do. Direito do Comércio Internacional: aspectos fundamentais. São Paulo: Aduaneiras, 2004, p. 59.
}

Revista Brasileira de Direito Internacional, Curitiba, v.7, n.7, jan./jun.2008 
Para Malynes, a lex mercatoria era definida como "a lei de todas as nações" e não de um Estado particular ${ }^{20}$ e parecia, então, ser baseada na lei romana, no costume marítimo e, também, nas leis das feiras medievais européias. Esses costumes comerciais se cristalizaram de tal forma que foram acolhidos, inclusive, pelas Cortes Inglesas, através do reconhecimento da então denominada law merchant.

Para Baddack, tal reconhecimento se dava ante o interesse dos soberanos e da população em geral em ter acesso aos produtos de mercados estrangeiros. O crescimento do comércio, então, era do interesse de todos e os comerciantes "estavam livres para definir suas próprias regras e não havia leis ou regulamentos impostos pelos soberanos". ${ }^{21}$

As diferenças existentes entre os sistemas legais de cada país trouxeram a necessidade, aos comerciantes internacionais, de encontrar um conjunto de regras universal, baseado nas necessidades mercantis da época. Tal conjunto, então, se estabeleceu a partir dos usos e costumes comerciais e era aplicado por cortes especiais, criadas para a solução de litígios havidos entre comerciantes.

As chamadas piepowder courts existiam em praticamente todos os mercados ingleses desde o século XIII ${ }^{22}$. Eram compostas por árbitros que tinham domínio da prática mercantil, e julgavam com agilidade e rapidez eventuais conflitos surgidos entre comerciantes, aplicando então esse conjunto de regras nascido da prática mercantil, denominado lex mercatoria.

Outras cortes medievais aplicavam, também, a denominada lex mercatoria, como as English Staple Courts, criadas em 1354 e as alemãs Bozner Merkantilgerichtsrat, criadas em 1635. O estatuto das English Staple Courts, por exemplo, estabelecia que "todos os comerciantes, ao chegar a

\footnotetext{
${ }^{20}$ MALYNES, G. Consuetudo Vel Lex Mercatoria or The Ancient Law Merchant. London: Adam Islip, 1622. p. 10 apud L. C. R. Costume Internacional: Gênese do Direito Internacional. Rio de Janeiro: Renovar, 2002. p. 287.

21 "To encourage tranding activities, merchants were free to set their own rules and no regulations or laws were imposed by the sovereigns". BADDACK, F. Lex Mercatoria: Scope and Application of the Law Merchant in Arbitration. Tese (LL.M., mode III) - Faculty of Law, University of the Western Cape, Cape Town, South Africa, 2005. p. 9

${ }^{22}$ GROSS, C. The Court of Piepowder. n.20,Quaterly Journal of Economics, 1906. p. 231-234 apud BADDACK, F. Lex Mercatoria: Scope and Application of the Law Merchant in Arbitration. Tese (LL.M., mode III) - Faculty of Law, University of the Western Cape, Cape Town, South Africa, 2005. p. 9.
}

Revista Brasileira de Direito Internacional, Curitiba, v.7, n.7, jan./jun.2008 
Staple, serão regulados pela lei mercante e não pela lei comum local, nem pelos usos e costumes das cidades, burgos ou outros locais". ${ }^{23}$

As cortes medievais eram em muito semelhantes às atuais cortes arbitrais. Eram compostas, em sua maioria, por comerciantes experientes e com amplo conhecimento da matéria que seria julgada, ao invés de juristas. Ainda, as cortes medievais também aplicavam uma lei transnacional adequada às necessidades comerciais da época e, assim como as cortes atuais, suas decisões eram cumpridas espontaneamente pelos comerciantes, os quais temiam desrespeitar uma decisão da corte e arriscar suas reputações perante a comunidade mercante internacional, podendo até mesmo ser excluídos da participação nas feiras medievais caso tal fato ocorresse. As cortes nacionais, então, eram raramente invocadas para a execução das decisões proferidas pelas cortes medievais.

Em suma, a lex mercatoria medieval era destinada a uma classe especial de pessoas e em locais específicos, ou seja, aos comerciantes em feiras, portos e mercados. Era distinta das legislações locais (de feudos, reinos e mesmo dos sistemas eclesiásticos), sendo, portanto, transnacional. Possuía como fonte principal os usos e costumes do comércio internacional e era aplicada principalmente pelos próprios comerciantes. ${ }^{24}$

\subsection{A LEX MERCATORIA CONTEMPORÂNEA}

Ainda na Idade Moderna, por volta dos séculos XVI e XVII, a lex mercatoria medieval passou a sofrer influências dos sistemas jurídicos locais e passou a refletir, também, os interesses políticos e econômicos de cada região. Com o absolutismo e o mercantilismo, a criação das normas que regeriam o comércio internacional não mais cabia aos comerciantes, mas sim às monarquias.

\footnotetext{
$23 " .$. all merchants coming to the staple ... shall be ruled by the law-merchant, as to all things touching the Staple, and not by the common law of the land, nor by usage of cities, boroughs, or other towns". ORDINANCE OF THE STAPLES. Disponível em <http://home.freeuk.net/donaitken/ast/e3b.htm|\#74>.

${ }^{24}$ BADDACK, F. Lex Mercatoria: Scope and Application of the Law Merchant in Arbitration. Tese (LL.M., mode III) - Faculty of Law, University of the Western Cape, Cape Town, South Africa, 2005. p. 10.
}

Revista Brasileira de Direito Internacional, Curitiba, v.7, n.7, jan./jun.2008 
Na França, o rei Luis XIV promoveu grandes reformas legislativas, dentre as quais se destacam a Ordennance sur le commerce de terre, em 1673, e a Ordennance sur le commerce de mer, em 1681, ambas codificando preceitos antes presentes no domínio da chamada lex mercatoria. Em 1807, ainda, a França publicou o seu Código Comercial, enfraquecendo ainda mais a atividade livre dos comerciantes. ${ }^{25}$

O princípio da liberdade, proclamado na Revolução Francesa, acabou por criar um clima favorável ao desenvolvimento do comércio internacional e, hoje, nota-se a robusta presença de tal principio nas relações comerciais internacionais.

O desenvolvimento da common law na Inglaterra, no século XVII, implicou em que os casos antes julgados pelas Cortes do Almirantado e outras cortes especializadas no julgamento de questões comerciais, fosse resolvidos pelas disposições da common law, sendo aquelas cortes extintas. Os usos e costumes deveriam, a partir de então, ser provados caso a caso e acabaram sendo incorporados por este regime jurídico.

Nesse período são promulgados dois importantes códigos ingleses, os quais também acabaram por absorver certos princípios da chamada lex mercatoria, a saber, o Bills of Exchange Act $^{26}$, de 1882 e o Sales of Goods Act $^{27}$, de 1893.

Posteriormente, a onda de codificações européias do século XIX acabou por incorporar muitos dos preceitos da chamada lex mercatoria, perdendo estes o seu caráter cosmopolita e tornado-se distantes da realidade quando confrontadas com os costumes mercantis. Para Amaral,

o conceito de Estado Nacional e lex mercatoria são praticamente excludentes, uma vez que o primeiro preceitua plena soberania ao Estado e o segundo a criação de um sistema de normas relativas ao

\footnotetext{
${ }^{25}$ STRENGER, I. Direito do Comércio Internacional e lex mercatoria. São Paulo: LTr, 1996. p. 60.

26 BILLS OF EXCHANGE ACT. Disponível em: http://www.opsi.gov.uk/RevisedStatutes/Acts/ukpga/1882/cukpga_18820061_en_1. Acesso em 05/08/2008.

${ }_{27}$ SALES OF GOODS ACT. Disponivel em: http://www.paclii.org/vu/legis/vuuk_act/soga1893128. Acesso em 05/08/2008.
}

Revista Brasileira de Direito Internacional, Curitiba, v.7, n.7, jan./jun.2008 
comércio internacional de caráter transnacional, ou seja, que se sobrepõe às fronteiras nacionais. ${ }^{28}$

A lex mercatoria, até então internacionalmente aceita, perde sua importância ante as inúmeras codificações que incorporaram os preceitos comerciais na Europa do século XIX, atribuindo à competência do Estado os conflitos até então solucionados pelas cortes dos comerciantes.

Após essa onda de codificações, os conflitos entre comerciantes passaram a ser resolvidos pelos órgãos nacionais, baseados nas leis nacionais, o que não agradou a comunidade mercantil da época. Lembra Baddack a indignação de Voltaire, em 1838:

Não é um absurdo e uma coisa terrível que aquilo que é verdade em uma cidade seja falso em outra? Que tipo de barbarismo é esse no qual cidadãos devem viver sob leis diferentes? ... Quando você viaja neste reino você troca de sistema jurídico tão freqüentemente quanto você troca de cavalos. ${ }^{29}$

A situação era agravada pela insegurança jurídica que passou a existir nos negócios internacionais, pois a partir de então, em uma situação eventual de conflito entre as partes, havia grandes dificuldades em se determinar qual a lei aplicável e qual corte julgaria o litígio. Mais uma vez, surge a necessidade de um conjunto de regras universal, independente das legislações estatais e que atendesse às necessidades da comunidade mercante como um todo. Surge, mais uma vez, a necessidade de uma "nova lei mercante". ${ }^{30}$

Após a segunda guerra mundial, com o rápido desenvolvimento da tecnologia, incluindo computadores, expansão do tráfego aéreo e produção em massa dos mais variados produtos, há um rápido desenvolvimento do comércio

\footnotetext{
${ }^{28}$ AMARAL, A. C. R. do. Direito do Comércio Internacional: aspectos fundamentais. São Paulo: Aduaneiras, 2004, p. 60.

29 "Is it not an absurd and terrible thing that what is true in one village is false in another? What kind of barbarism is it that citizens must live under different laws? ... When you travel in this kingdom you change legal systems as often as you change horses". VOLTAIRE, Oeuvres de Voltaire VIII, 1838. p. 8. apud BADDACK, F. Lex Mercatoria: Scope and Application of the Law Merchant in Arbitration. Tese (LL.M., mode III) - Faculty of Law, University of the Western Cape, Cape Town, South Africa, 2005. p. 13.

30 STRENGER, I. Direito do Comércio Internacional e Lex Mercatoria. São Paulo: LTr, 1996. p. 62.
}

Revista Brasileira de Direito Internacional, Curitiba, v.7, n.7, jan./jun.2008 
internacional. Percebe-se, então, que os usos e costumes internacionais, bem como os contratos-tipo elaborados por associações de comércio ganham relevância.

A partir da década de 20 os contratos internacionais de âmbito privado passam a utilizar cláusulas e compromissos arbitrais com maior freqüência, retirando a competência para solução de conflitos do âmbito estatal, movimento esse que cresce essencialmente após a II Guerra Mundial. As falhas das legislações nacionais são mais uma vez expostas, um número considerável de convenções e tratados, não baseados em qualquer lei estatal, passam a ser utilizados nos campos da arbitragem e do direito comercial em geral e a supremacia das leis nacionais passa a ser questionada.

Assim como os comerciantes medievais, os atores do comércio internacional contemporâneo passaram a adotar soluções alternativas para evitar a aplicação de qualquer lei nacional aos contratos por eles celebrados, utilizando cláusulas padrão, contratos-tipos e costumes comerciais para regular os conflitos existentes, agora submetidos às câmaras de arbitragem internacionais.

A London Corn Trade Association utiliza contratos-tipo e cláusulas

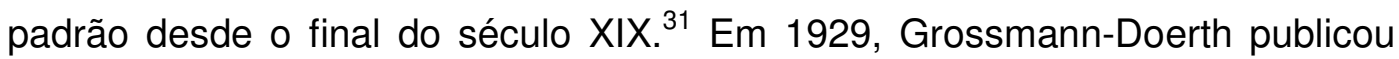
um artigo no qual descreve a formação de um sistema autônomo de comércio, o qual incluía usos e costumes, contratos e clausulas-padrão e regras uniformes desenvolvidas e publicadas por organizações internacionais, bem como que esse sistema era alimentado basicamente pela comunidade mercante, e não por juristas e legisladores de quaisquer Estados Nacionais. ${ }^{32}$

Em 1935, Lambert discorre sobre o renascimento da lei mercante, a qual estaria se desenvolvendo sem a interferência dos legisladores nacionais:

Nascida como a lei mercante medieval unicamente através dos fatores econômicos, e sem qualquer ratificação das autoridades estatais, este

${ }^{31}$ STRENGER, I. Direito do Comércio Internacional e Lex Mercatoria. São Paulo: LTr, 1996. p. 62.

32 BADDACK, F. Lex Mercatoria: Scope and Application of the Law Merchant in Arbitration. Tese (LL.M., mode III) - Faculty of Law, University of the Western Cape, Cape Town, South Africa, 2005. p. 17.

Revista Brasileira de Direito Internacional, Curitiba, v.7, n.7, jan./jun.2008 
novo direito comercial criado pelos comerciantes tem, como a lei mercante medieval, a aptidão de se expandir livremente para além das fronteiras nacionais. Ela possui desde sua origem um caráter cosmopolita, pois as atividades comerciais e industriais, a partir das quais ela é invocada a reger o jogo, são elas mesmas atividades internacionais. ${ }^{33}$

Em um artigo denominado La Compagnie de Suez, societé internationale, publicado no jornal Le Monde de 04 de outubro de 1965, Berthold Goldman discorre sobre a possibilidade de uma empresa multinacional ser governada por uma lei desvinculada de qualquer Estado. ${ }^{34}$

Nos anos 60, outros protagonistas do direito comercial internacional passaram a invocar a existência dessa nova lex mercatoria. Os primeiros trabalhos sobre o tema foram desenvolvidos por Fragitstas, Goldstajn, Schmitthoff, Goldman, Khan e Fouchard ${ }^{35}$

Um dos trabalhos mais importantes sobre o tema foi publicado em 1964, por Berthold Goldman, na revista Archives de Philosophie du Droit. O artigo, denominado Frontières du Droit et lex mercatoria, define a lei mercatoria como um conjunto de princípios, instituições e regras com origem em diversas fontes, o qual rege as relações de um determinado grupo de pessoas; os comerciantes internacionais. ${ }^{36}$

Seria, portanto, a solução encontrada pelos comerciantes internacionais para escapar aos obstáculos que surgem da aplicação das

\footnotetext{
33 "Né comme la loi marchande médiévale de la seule force des faits économiques, et sans aucune consécration d’autorités étatiques territoriales, ce nouveau droit commercial fait par les commerçants a, comme la loi marchande médiévale, l'aptitude à se répandre librement par dessus les frontiéres des Etats et des nationalités. II prend dès as naissance um caractère accusé de cosmopolitisme, parce que les activités commerciales ou industrielles, dont il est appelé à régler le jeu, sont elles-mêmes des activités internationales". LAMBERT, E. Sources du Droit Comparé ou supra-national. Legilslation uniforme et jurisprudence comparative, 1934. p. 498. apud BADDACK, F. Lex Mercatoria: Scope and Application of the Law Merchant in Arbitration. Tese (LL.M., mode III) - Faculty of Law, University of the Western Cape, Cape Town, South Africa, 2005. p. 18.

${ }^{34}$ BADDACK, F. Lex Mercatoria: Scope and Application of the Law Merchant in Arbitration. Tese (LL.M., mode III) - Faculty of Law, University of the Western Cape, Cape Town, South Africa, 2005. p. 19.

${ }^{35}$ BERGER, Klaus Peter. The Creeping Codification of the Lex Mercatoria. Hague: Kluwer Law International, 1999. p. 2.

${ }^{36}$ STRENGER, I. Direito do Comércio Internacional e lex mercatoria. São Paulo: LTr, 1996. p. 71-76.
}

Revista Brasileira de Direito Internacional, Curitiba, v.7, n.7, jan./jun.2008 
legislações nacionais aos conflitos que envolvem partes de países que, por vezes, possuem sistemas jurídicos diversos.

O mesmo autor, em 1993 retoma o assunto, mencionando que há muitos anos é possível constatar que

As relações econômicas internacionais são efetivamente governadas, inteira ou parcialmente, pelos princípios, regras e pelos usos e costumes transnacionais, formados espontaneamente e adotados na conclusão das negociações, sem que qualquer autoridade estatal ou interestatal as tenham imposto - e esta é a lex mercatoria. ${ }^{37}$

O século XX, então, se caracteriza por uma crescente internacionalização do comércio, a qual acabou por demonstrar que as necessidades da comunidade mercantil internacional não são satisfeitas pelas leis nacionais, as quais acabam por interferir negativamente no crescimento global do comércio. Há, portanto, a necessidade de se desenvolver regras que possam ser aplicadas em quaisquer Estados, independentemente do direito interno do Estado no qual ocorra o conflito.

\section{ASPECTOS GERAIS DA NOVA LEX MERCATORIA}

Desde que a doutrina identificou a existência da chamada nova lex mercatoria, seu conceito, conteúdo e natureza têm sido amplamente discutidos. Para Berger ${ }^{38}$, podem ser resumidas em três as teorias existentes em torno da lex mercatoria.

A primeira delas a considera como um conjunto de princípios e regras esparsos e inconsistentes, sem a qualidade de "sistema", servindo apenas de complemento à aplicação da lei doméstica. A validade e eficácia desses princípios variam, ainda, de acordo com o sistema jurídico de cada estado.

\footnotetext{
37 “(...) les relations économiques internationales sont effectivement gouvernées, entièrement ou partiellement, par des principles, des règles et des usages transnationaux, spontanément formés ou adoptés dans la conclusion et le fonctionnement des ces relations, sans qu'une autorité étatique ou interétatique les aient imposes - et c'est cela la lex mercatoria." GOLDMAN, B. Nouvelles Réflexions sur la Lex Mercatoria. Festschrift Pierre Lalive, Basel. Frankfurt: a.M., 1993. p. 244.

${ }^{38}$ BERGER, Klaus Peter. The Creeping Codification of the Lex Mercatoria. Hague: Kluwer Law International, 1999. p 40.
}

Revista Brasileira de Direito Internacional, Curitiba, v.7, n.7, jan./jun.2008 
Já uma segunda vertente considera a lex mercatoria como a totalidade dos usos e costumes que são refinados de acordo com as necessidades do comércio internacional, constituindo um ius commune de fato.

O terceiro e último conceito, para Berger, considera a lex mercatoria como sistema jurídico independente e supranacional, justificado e validado tanto por seu caráter autônomo quanto pela autonomia da vontade das partes ao celebrar contratos. A maioria da doutrina que sustenta esse ponto de vista, para Berger, coloca o sistema jurídico transnacional entre o sistema jurídico nacional e o sistema jurídico internacional público.

Para Molineaux, o primeiro conceito é denominado "mínimo", enquanto o terceiro recebe o adjetivo de "máximo" e tem o papel de auxiliar árbitros e juízes ao decidir conflitos no âmbito do comércio internacional, em especial quando a lei aplicável é insuficiente ou inexistente. ${ }^{39}$

Os dois primeiros pontos de vista, ao considerar a lex mercatoria como um mero conjunto de regras e princípios heterogêneo, não implicam necessariamente em conflitos com o sistema jurídico nacional, pois não compreendem a lex mercatoria como um sistema autônomo e passível de ser aplicado aos conflitos internacionais independentemente de algum sistema jurídico nacional. Tais visões sobre o conceito da nova lei mercante a tomam em seu significado medieval, como um conjunto de regras e princípios internacionalmente conhecidos composto apenas de certos usos e costumes não claramente definidos.

O terceiro, entretanto, que considera a lex mercatoria como um sistema jurídico supranacional além dos já conhecidos sistemas jurídicos nacionais e do sistema jurídico internacional, há anos é alvo de críticas e será, portanto, objeto de estudo mais aprofundado neste trabalho. Antes, porém, necessário apresentar e discorrer brevemente sobre as fontes e sobre o conteúdo que formam tal sistema.

\subsection{AS FONTES E O CONTEÚDO DA LEX MERCATORIA}

\footnotetext{
${ }^{39}$ MOLINEAUX, Charles. Moving toward a lex mercatoria: a lex constructionis. International Arbitration, n. 1, 1997. p. 56.
}

Revista Brasileira de Direito Internacional, Curitiba, v.7, n.7, jan./jun.2008 
Apesar de alguns doutrinadores diferenciarem as fontes do conteúdo da lex mercatoria, entende Goldman que tal distinção não possui um significado verdadeiramente relevante. Para ele, a analise do conteúdo da lex mercatoria não deveria partir senão da aplicação das fontes pela jurisprudência arbitral. ${ }^{40}$

Essas fontes ou elementos que compõe a Lei Mercante não podem ser descritos exaustivamente, mas alguns elementos são comumente apontados pela doutrina como existentes e válidos no âmbito do comércio internacional. ${ }^{41}$

Para Baddack ${ }^{42}$, as fontes da Lei Mercante podem ser visualizadas de duas maneiras distintas: de um ponto de vista amplo ou de um ponto de vista estrito. Os defensores deste ponto de vista consideram apenas o caráter espontâneo e não estatutário da lex mercatoria, ou seja, excluem as convenções internacionais. A ênfase é dada no caráter a-nacional da Lei Mercante, desvinculado das legislações nacionais. Assim, as convenções internacionais e legislações uniformes não poderiam ser parte dela, pois, em geral, entram em vigor e ganham eficácia através de leis nacionais.

A visão ampla, por sua vez, define lex mercatoria como sendo uma lei transnacional e coloca menos ênfase no seu caráter espontâneo. Assim, todas as normas aplicáveis ao comércio internacional seriam, também, parte da Lei Mercante. Os defensores deste ponto de vista em geral argumentam que o comércio internacional não segue, atualmente, as legislações de algum país em específico mas, ao contrário, executam uma espécie de "auto regulação" e criam suas próprias regras, para evitar conflitos entre os diferentes sistemas jurídicos dos estados representados em uma relação contratual. Seriam,

\footnotetext{
40 "Mais on voit que la distinction [entre les sources et le contenu] n'a de veritable signification que partielle. Celle-ci résulte du fait que la determination des sources peut être fait à partir de critères différents, qui demeurent controversés, alors que celle du contenu ne découle, ou ne devrait découler, que de l'analyse des composantes des sources retenues, et en particulier de celles qui sont utilisées par la jurisprudence arbitrale, principalement mais point exclusivement". GOLDMAN, B. Nouvelles Réflexions sur la Lex Mercatoria. Festschrift Pierre Lalive, Basel. Frankfurt: a.M., 1993. p. 243

${ }^{41}$ "It is not possible to provide an exhaustive list of all elements of the "law merchant". LANDO, O. The law applicable to the merits of the dispute. In: SARCEVIC, P. (ed), Essays on International Commercial Arbitration. Boston, London: 1991. p.144.

${ }^{42}$ BADDACK, F. Lex Mercatoria: Scope and Application of the Law Merchant in Arbitration. Tese (LL.M., mode III) - Faculty of Law, University of the Western Cape, Cape Town, South Africa, 2005. p. 55.
}

Revista Brasileira de Direito Internacional, Curitiba, v.7, n.7, jan./jun.2008 
portanto, fontes da lex mercatoria as convenções internacionais, os princípios gerais do direito, os códigos de conduta internacionais, usos e costumes, os contratos e cláusulas-padrão, e as regras emanadas de organizações internacionais.

Essa visão mais ampla das fontes da lex mercatoria parece ser a mais adequada para os objetivos deste trabalho, principalmente porque, como afirma Baddack, em resposta à crítica de Lagarde, o fato de um princípio integrar a chamada Lei Mercante não o impede de ser absorvido por alguma legislação nacional. $^{43}$

Seguindo essa vertente, Schmitthoff visualiza duas categorias de fontes da lex mercatoria, aquelas provenientes da legislação internacional e aquelas provenientes dos usos e costumes do comércio internacional. ${ }^{44}$ Lew, por sua vez, identifica três diferentes fontes: as regras substantivas de comércio internacional, os manuais de prática para o comércio internacional e os usos e costumes, em geral, do comércio internacional. ${ }^{45}$

A lista de fontes mais aceita e citada pela doutrina em geral, porém, foi elaborada pelo professor Ole Lando, para quem há basicamente sete fontes fundamentais da Lei Mercante.

O Direito Internacional Público, em sentido lato, que apesar de constituir um sistema jurídico distinto e autônomo que interage com os sistemas jurídicos nacionais, seria a primeira destas fontes. Lando crê que as

\footnotetext{
43 "How can one rule of a certain system of law cease to be part of it and be transformed into a rule of a given national law through the mere act of its incorporation into the latter? The fact that a rule is part of the lex mercatoria does not exclude the possibility of that rule or principle being incorporated into some national law". BADDACK, F. Lex Mercatoria: Scope and Application of the Law Merchant in Arbitration. Tese (LL.M., mode III) - Faculty of Law, University of the Western Cape, Cape Town, South Africa, 2005. p. 55.

${ }^{44}$ SCHMITTHOFF, C., Das neue recht des Welthandels. Rabels Zeitschrift fur auslandisches un internationales privatrecht. 1964, p 28. apud BADDACK, F. Lex Mercatoria: Scope and Application of the Law Merchant in Arbitration. Tese (LL.M., mode III) - Faculty of Law, University of the Western Cape, Cape Town, South Africa, 2005. p. 55.

${ }^{45}$ LEW, J. D. M. Applicable law in international commercial arbitration. New York: 1978. p. 442. apud BADDACK, F. Lex Mercatoria: Scope and Application of the Law Merchant in Arbitration. Tese (LL.M., mode III) - Faculty of Law, University of the Western Cape, Cape Town, South Africa, 2005. p. 55.
}

Revista Brasileira de Direito Internacional, Curitiba, v.7, n.7, jan./jun.2008 
disposições desse sistema devem também ser aplicadas às disputas envolvendo empresas privadas, e não apenas às disputas entre Estados. ${ }^{46}$

As convenções internacionais são também importante fonte da lex mercatoria e vêm sendo amplamente utilizadas pelos comerciantes internacionais. As disposições encontradas nas convenções assinadas sob a égide do Institut pour l'Unification du Droit (UNIDROIT), da United Nations Commission on International Trade Law (UNCITRAL) e da United Nations Convention on Contracts for the International Sale of Goods (CISG) são amplamente utilizadas como fonte de interpretação dos contratos internacionais e constituem-se, portanto, em fontes da denominada Lei Mercante.

Os princípios gerais do direito, previstos no art. 38 do Estatuto da Corte Internacional de Justiça como fonte do Direito Internacional lato sensu, dentre os quais se encontra o pacta sunt servanda, a boa fé e a clausula rebus sic standibus, são também apontados por Lando como fonte da lex mercatoria. Apesar das dificuldades em se determinar quais regras são qualificadas como princípios gerais, atualmente os meios para defini-los têm evoluído significativamente, com base em estudos comparativos dos diversos sistemas jurídicos e de quais princípios gerais integram cada qual. ${ }^{47}$

Goldman sublinha que,

(...) dentre os princípios, acabamos de mencionar o pacta sunt servanda. À ele, podemos anexar (...) a limitação por uma cláusula implícita de rebus sic stantibus; a obrigação de executar os contratos com boa-fé; (...) a obrigação em reparar integralmente um prejuízo previsível; a aplicação do princípio ut res magis valeat quam pereat. ${ }^{48}$

\footnotetext{
46 "Rules of public international law may also be applied to disputes between private enterprises". LANDO, O. The Law Applicable to the Merits of the Dispute. In: SARCEVIC, P. (ed.). Essays on International Commercial Arbitration. Boston, London: 1991. p. 145.

47 "It is not easy to ascertain which rules are general principles; however, the possibilities of doing so are improving with the growing volume of literature an comparative law". LANDO, O. The Law Applicable to the Merits of the Dispute. In: SARCEVIC, P. (ed.). Essays on International Commercial Arbitration. Boston, London: 1991. p. 145.

48 "Parmi les principles, on vient de mentioner pacta sunt servanda. On pourrait y ajouter - si elle était généralement admise - la limitation de ce principe par une clause implicite de rebus sic stantibus; l'obligation d'exécuter les contrats de bonne foi; (...) l'obligation de réparer intégralement le prejudice prévisible; l'application du principe ut res magis valeat quam pereat'. GOLDMAN, B. Nouvelles Réflexions sur la Lex Mercatoria. Festschrift Pierre Lalive, Basel. Frankfurt: a.M., 1993. p. 241
}

Revista Brasileira de Direito Internacional, Curitiba, v.7, n.7, jan./jun.2008 
Certas organizações internacionais, como a United Nations Conference on Trade and Development (UNCTAD), a United Nations Commission on International Trade Law (UNCITRAL) e a Organisation for Economic Cooperation and Development (OECD), dentre outras, têm proferido recomendações, resoluções, pareceres e códigos de conduta sobre determinados assuntos relacionados a contratos internacionais. Tais documentos, que não vinculam quaisquer países ou pessoas, são também considerados por Lando como fontes da Lei Mercante. Como exemplo, menciona Baddack o OECD Guidelines for Multinational Enterprises, criado em 1971. De acordo com a definição da OECD,

\begin{abstract}
As "guidelines" consistem em um conjunto de recomendações endereçadas por governos às empresas multinacionais que tenham relações comerciais com os países que aderentes. Elas provêem princípios e padrões voluntários para uma conduta responsável em negócios nas mais diversas áreas, incluindo relações de emprego e industriais, direitos humanos, meio ambiente, informações confidenciais, competição, impostos, ciência e tecnologia. ${ }^{49}$
\end{abstract}

Os usos e costumes são também apontados como fontes da lex mercatoria. Cabe salientar, os vocábulos "usos" e "costumes" possuem significados diversos e não devem ser confundidos. Os costumes, regra geral, são aplicados sem o consentimento das partes, enquanto os usos devem ser escolhidos e explicitamente referidos pelas partes para que sejam aplicáveis ao contrato entre elas celebrado. ${ }^{50}$ Lando considera, ainda, que ambos podem ser utilizados como referência por árbitros e juízes, mesmo quando as partes não houverem disposto em contrato sobre sua aplicação. ${ }^{51}$

\footnotetext{
49 "The Guidelines are recommendations addressed by governments to multinational enterprises operating in or from adhering countries. They provide voluntary principles and standards for responsible business conduct in a variety of areas including employment and industrial relations, human rights, environment, information disclosure, combating bribery, consumer interests, science and technology, competition, and taxation". OECD Guidelines for Multinational Enterprises. Disponível em http://www.oecd.org/daf/investment/guidelines/.

${ }^{50}$ DE LY, F. International Business Law and lex mercatoria, 1992. apud BADDACK, F. Lex Mercatoria: Scope and Application of the Law Merchant in Arbitration. Tese (LL.M., mode III) Faculty of Law, University of the Western Cape, Cape Town, South Africa, 2005. p. 69.

${ }^{51}$ LANDO, O. The Law Applicable to the Merits of the Dispute. In: SARCEVIC, P. (ed.). Essays on International Commercial Arbitration. Boston, London: 1991. p. 146.
}

Revista Brasileira de Direito Internacional, Curitiba, v.7, n.7, jan./jun.2008 
Os contratos-tipo, ou contratos-padrão, desenvolvidos por organizações comerciais constituem também uma das fontes da nova lex mercatoria. Um contrato (ou cláusula) padrão consiste em um modelo préestabelecido de contrato (ou cláusula) confeccionado e divulgado por certas organizações comerciais. Em geral, é utilizado por empresas que não possibilitam à outra parte discutir cláusulas e condições, às quais cabe apenas aderir ou não ao contrato.

A London Corn Trade Association utiliza contratos-padrão desde $1878^{52}$. Em 1971, uniu-se à Cattle Food Trade Association formando a Grain and Feed Trade Association (GAFTA), a qual ainda hoje fornece clausulas e contratos-padrão aos seus membros. Há, ainda, a International Air Transport Association (IATA) e a Fédération Internationale des Ingénieurs-Conseils (FIDIC) como importantes associações nesse quesito.

Por fim, são também os laudos arbitrais considerados fontes da denominada lex mercatoria. Tal se deve ao fato de, em geral, a arbitragem ser utilizada para resolver litígios envolvendo partes de Estados diferentes e, conseqüentemente, vinculadas a sistemas jurídicos distintos, o que raramente ocorre em julgamentos realizados por cortes nacionais.

O árbitro, então, além de observar e constatar usos, costumes e princípios gerais que se aplicam ao caso, por vezes "cria", na expressão utilizada por Osman $^{53}$, o direito a ser aplicado ao caso concreto e, assim, constituem-se os laudos arbitrais uma das mais importantes fontes da Lei Mercante.

Percebe-se, enfim, que a lex mercatoria não pode ser reduzida a um simples conjunto de usos e costumes ou mesmo a um simples conjunto de princípios gerais do direito, como querem alguns autores. Não obstante a impossibilidade em se enumerar exaustivamente as fontes e o conteúdo da Lei Mercante, não se pode minimizar seu papel no Comércio Internacional.

\footnotetext{
52 STRENGER, I. Direito do Comércio Internacional e Lex Mercatoria. São Paulo: LTr, 1996. p. 62.

${ }^{53}$ OSMAN, F. Les Principes Généraux de la lex mercatoria. Paris; LDDJ, 1992. p. 15. apud BADDACK BADDACK, F. Lex Mercatoria: Scope and Application of the Law Merchant in Arbitration. Tese (LL.M., mode III) - Faculty of Law, University of the Western Cape, Cape Town, South Africa, 2005. p. 80.
}

Revista Brasileira de Direito Internacional, Curitiba, v.7, n.7, jan./jun.2008 


\subsection{A LEX MERCATORIA COMO SISTEMA JURÍDICO AUTÔNOMO}

A falta de um conceito claro e bem definido sobre o que seria a lex mercatoria, qual seu conteúdo e qual sua natureza jurídica pode ser um dos principais fatores geradores de críticas ao modelo apresentado. Lembra Strenger, entretanto, que

"como a lex mercatoria é uma realidade, somente pode haver controvérsia em torno de sua natureza, mas é incontestável o fato de que sua incursão se realiza acima e além das fronteiras nacionais, criando, de modo mais ou menos completo, um conjunto de regras observáveis em maior ou menor dose, segundo o seu campo de aplicação". 54

Muitas críticas foram feitas às teorias em prol da lex mercatoria. Para Antoine Kassis, por exemplo, "a lex mercatoria não existe com as estruturas e significações que the dão seus defensores" ${ }^{55}$. Lagarde, por sua vez, restringia o conteúdo e as fontes da lex mercatoria, pois os princípios gerais do direito, previstos no art. 38 do Estatuto da Corte Internacional de Justiça, e os Tratados e Convenções Internacionais são fontes de Direito Internacional Público e, assim, não poderiam integrar o escopo da Lei Mercante. Para ele, ainda, a lex mercatoria não poderia ser considerada um sistema jurídico autônomo, eis que suas fontes e conteúdos não poderiam ser definidos claramente e, ainda, ante o fato de não haver uma única comunidade de comerciantes internacionais, mas sim diversas sub-comunidades, o que implicaria a existência de tantas lex mercatoria's quantas sub-comunidades existissem. ${ }^{56}$

Para Berger, todas as discussões até então havidas podem ser resumidas em apenas uma, qual seja, a de que a lex mercatoria não constitui um genuíno "sistema jurídico". Alega-se que a prática mercantil, baseada na

\footnotetext{
${ }^{54}$ STRENGER, I. Direito do Comércio Internacional e Lex Mercatoria. São Paulo: LTr, 1996. p. 79.

${ }^{55}$ STRENGER, I. Direito do Comércio Internacional e Lex Mercatoria. São Paulo: LTr, 1996. p. 121.

${ }^{56}$ LAGARDE, P. Approche critique de la lex mercatoria. Le Droit des relations économiques internacionales: Etudes offerts à Berthold Goldman. Paris: litec, p. 125-150, 1987.
}

Revista Brasileira de Direito Internacional, Curitiba, v.7, n.7, jan./jun.2008 
concepção pragmática do Direito Romano de que o principal objetivo de um sistema jurídico é prover a sociedade com meios para a solução de conflitos (ubi societas, ibi ius), não possui base teórica suficiente para constituir um sistema jurídico transnacional. Ainda, alega-se que os esforços para tanto são esparsos $^{57}$.

Em 1964, Berthold Goldman foi um dos precursores a defender a idéia de que as regras que compõe a chamada lex mercatoria constituiriam um sistema jurídico próprio, destinado aos comerciantes internacionais.

Para tanto se faz necessário, em primeiro lugar, verificar o conceito de "sistema jurídico" apresentado por Goldman. Para ele, o caráter de regras não pode ser recusado aos elementos constitutivos da lex mercatoria, bem como afirma que esta cumpre a função de um conjunto de regras de direito. Lembra Huck que

\footnotetext{
"Neste ponto, [Goldman] lembrava a consagrada definição de Batiffol, que considera a norma jurídica como uma prescrição de caráter geral, formulada com suficiente precisão, para que os interessados possam conhecê-la antes de agir. Para Goldman, a lex mercatoria, tal como então se apresentava, respondia quase integralmente aos requisitos prescritos por Batiffol., ${ }^{, 5}$
}

A lex mercatoria é, para Goldman, um conjunto de princípios a regras que tinha origem em um processo espontâneo de criação legislativa, não vinculado a qualquer sistema jurídico nacional e que escapa ao domínio dos legisladores nacionais, cuja competência finda nos limites territoriais de sua jurisdição. ${ }^{59}$

Desde então, a doutrina defensora de um sistema jurídico autônomo e a-nacional do direito do comércio internacional vem se destacando sobre a doutrina tradicionalista.

\footnotetext{
57 BERGER, K. P. The Creeping Codification of the Lex Mercatoria. Hague: Kluwer Law International, 1999. p. 89.

${ }^{58}$ HUCK, H. M. Sentença Estrangeira e Lex Mercatoria: horizontes e fronteiras do comércio internacional. São Paulo: Saraiva, 1994. p. 106.

${ }^{59}$ BERGER, K. P.. The New Law Merrchant and the Global Market Place - A 21st Century View of Transnational Commercial Law. Disponível em: <http://tldb.uni-koeln.de>. Acesso em 05/08/2008.
}

Revista Brasileira de Direito Internacional, Curitiba, v.7, n.7, jan./jun.2008 
Para Teubner, ainda, a lex mercatoria é concebida como uma "Lei Global sem Estado", que se manifesta em um sistema jurídico que não deve ser contraposto ou mesmo comparado aos sistemas jurídicos nacionais. ${ }^{60}$

As principais objeções que se fazem a essa proposição, como a de que acordos privados não podem produzir Lei sem autorização do controle Estatal e a de que não há Lei senão aquela aplicada no âmbito nacional devem ser refutadas para Teubner. Para ele, regras e princípios podem ser produzidos por processos políticos, legais ou mesmo sociais e, neste caso, a lex mercatoria seria produzida na "periferia" do processo legislativo ao invés do "centro" concebido pela teoria tradicionalista, através da interação de entidades que atuam no comércio internacional.

A força do contrato e a função dos tribunais arbitrais estão no centro desse "processo legislativo" e, assim, ao tornar o impossível possível o contrato consiste em uma genuína fonte do direito. A base desse sistema jurídico autônomo estaria, então, no mecanismo de controle exercido pelos tribunais arbitrais, o qual é possível através da vontade das partes em submeter litígios futuros às cortes arbitrais e nas disposições de institutos internacionais como a ICC e o UNIDROIT, concebidos por Teubner como "legisladores privados".

A crítica de Lagarde, de que a lex mercatoria era composta de princípios e regras vagos e ambíguos ${ }^{61}$ é também contestada por Teubner. Para ele, não é a existência de um conjunto de regras e princípios bem estruturado e definido que caracterizará a viabilidade da doutrina que defende o direito transnacional, mas sim a aceitação de um processo de criação de leis auto-organizado pela própria comunidade mercantil.

A flexibilidade da lex mercatoria, ainda, concede ao sistema jurídico estabilidade e a possibilidade de se adaptar rapidamente às mudanças no cenário do comércio internacional, ao invés da insegurança jurídica mencionada por Lagarde.

\footnotetext{
${ }^{60}$ TEUBNER, G. Global Bukowina: Legal Pluralism in the World-Society. Global Law Without a State. Burlington: Ashgate, 2003. Disponível em: http://ssrn.com/abstract=896478.

${ }^{61}$ LAGARDE, P. Approche critique de la lex mercatoria. Le Droit des relations économiques internacionales: Etudes offerts à Berthold Goldman. Paris: litec, p. 125-150, 1987
}

Revista Brasileira de Direito Internacional, Curitiba, v.7, n.7, jan./jun.2008 
Não obstante toda a discussão havida pela doutrina até então quanto a este tema, lembra Berger que a importância da noção de sistema e de sua atribuição à lex mercatoria é apenas relativa. ${ }^{62}$ Isto significa dizer que a existência de um sistema jurídico completo e autônomo não é condição necessária e essencial para que suas regras e princípios sejam aplicadas.

Até porque os próprios sistemas jurídicos domésticos não são completos em si mesmos e, como se sabe, suas falhas são suprimidas pelo juiz ao analisar o caso concreto, com base em princípios gerais do direito muitas vezes não definidos claramente na legislação nacional. Berger lembra ainda que

Quando aplicamos estas considerações ao plano transnacional, devemos considerar as características particulares deste conjunto de regras e princípios que o torna diferente de qualquer sistema jurídico nacional. Nós não estamos lidando com um sistema completo e que se basta em si mesmo. Ao contrário, a lei transnacional é um claro exemplo de uma law in the making. ${ }^{63}$

Há, então, uma mudança de paradigmas. A teoria tradicional, que concebia a noção de sistema jurídico vinculada à noção de soberania Estatal aos poucos é substituída por um pluralismo jurídico que aceita a habilidade da sociedade de se auto-organizar e coordenar.

É necessário, portanto, desvincular-se da noção de Estado e de soberania para compreender a lex mercatoria como sistema jurídico autônomo e independente, cujas características são diversas e não devem ser comparadas aos sistemas jurídicos nacionais.

\section{NOVAS TENDÊNCIAS RUMO À CODIFICAÇÃO DO DIREITO DO COMÉRCIO INTERNACIONAL}

\footnotetext{
${ }^{62}$ BERGER, K. P. The Creeping Codification of the Lex Mercatoria. Hague: Kluwer Law International, 1999. p. 92.

${ }^{63}$ "When applying these considerations to transnational plane, one has to start by taking into account the particular characterist of this law which makes it different from any domestic legal system. We are not dealing here with a 'complete' and self-contained sophisticated legal system. Instead, transnational law provides the example par excellence for a 'law in the making'. BERGER, K. P. The Creeping Codification of the Lex Mercatoria. Hague: Kluwer Law International, 1999. p. 92.
}

Revista Brasileira de Direito Internacional, Curitiba, v.7, n.7, jan./jun.2008 
Os esforços para a unificação do Direito Internacional Privado são há muito conhecidos. Ao longo do século XX, cientistas e entidades privadas realizaram e ainda realizam estudos com o objetivo de promover a unificação da legislação relativa aos contratos internacionais.

As discussões teóricas até então havidas em torno do conceito, fontes e conteúdo da lex mercatoria em muito influenciaram a criação desses projetos, cujo principal objetivo era conceber uma legislação uniforme ou ao menos harmônica para as relações comerciais internacionais.

Tais projetos, para Symeonides, consistiam em normas informais possuidoras de certas características de Lei, as quais não são novas ou sequer um fenômeno incomum:

O que é novo é o surgimento de uma nova espécie de norma informal ou não-estatal que não possuem os atributos necessários das normas em geral, i.e., uma prática espontânea comum que se repete por certo tempo (longa consuetudo) e geralmente aceita como possuidora de força tácita e consenso comum (opinio juris). ${ }^{64}$

Por "nova espécie" entendem-se as publicações realizadas por organismos privados, em geral sem veículo com o governo de quaisquer países e sem interesses econômicos e que se apresentaram, ao longo da história, basicamente de três maneiras distintas: (i) negociações bilaterais, como o Projeto de Código das Obrigações e dos Contratos Franco-Alemão (projet de code des obligations et des contrats), de 1917, (ii) regionais, como o American Restatement of the Law of Contracts, de 1932 e o Projeto de Código Civil Europeu, iniciado em 1990 ou (iii) mundiais, como o Núcleo Comum dos Sistemas Jurídicos, de 1968 e o Projeto UNIDROIT de codificação progressiva, iniciado em $1971 .^{65}$

\footnotetext{
64 "What is new $s$ the emergence of a new species of informal or non-state norms that do not possess the necessary attributes $f$ custom, i.e., a usually spontaneous practice repeated for a long time (longa consuetude) and generally accepted as having acquired the force of tacit and common consent (opinion juris). SYMEONIDES, Symeon C. Party Autonomy and Private-Law Making in Private International Law: The Lex Mercatoria that Isn't. 2006. P. 4.

${ }^{65}$ BERGER, K. P. The Creeping Codification of the Lex Mercatoria. Hague: Kluwer Law International, 1999. p. 117-140.
}

Revista Brasileira de Direito Internacional, Curitiba, v.7, n.7, jan./jun.2008 
Tais projetos, em suma, propõem a consolidação através da (i) harmonização das leis, (ii) da uniformização destas ou, ainda, da (iii) codificação de preceitos comuns aos países envolvidos.

A harmonização, em regra, consiste na aproximação da legislação de diversos países de forma flexível, dentro dos limites necessários para atingir um objetivo comum. É o procedimento que possibilita a redução gradativa existente entre as diferenças havidas, da forma mais branda possível, através de modelos legislativos em geral não vinculativos. Cada Estado adotará os dispositivos constantes do modelo padrão de acordo com seus próprios critérios de oportunidade e de conveniência. ${ }^{66}$

O American Restatement of the Law of Contracts é um exemplo desse modelo, editado pelo American Law Institute em 1932, o qual procurava superar a incerteza e a complexidade da lei americana. ${ }^{67}$ Tratava-se de um texto especializado que reunia os princípios mais importantes consagrados pela práxis norte-americana no tocante às transações comerciais de forma clara e precisa.

Já a uniformização propõe a reunião, em um único instrumento, de elementos, regras ou princípios antes dispersos. Em suma, visa transformar dois ou mais textos legislativos distintos em um único texto válido para todas as partes envolvidas. Tal modelo, enfatiza Basedow ${ }^{68}$, entrou em crise no decorrer do século XX por sua difícil aplicação prática, em especial por não considerar os aspectos culturais dos Estados envolvidos e por reduzir em muito as possibilidades de evolução dos sistemas jurídicos dos Estados envolvidos. A CISG, editada em 1980 através de convenção emanada da ONU, foi uma das primeiras tentativas de uniformizar as legislações dos países signatários.

\footnotetext{
${ }^{66}$ PESSÔA, F. J. B. A consolidação da lex mercatoria como forma de harmonização do direito privado. Dissertação (Mestrado em Direito). Centro de Ciências Jurídicas e Sociais. Pontifícia Universidade Católica do Paraná. Curitiba, 2006. p. 32.

67 BERGER, K. P. The Creeping Codification of the Lex Mercatoria. Hague: Kluwer Law International, 1999. p. 120.

${ }^{68}$ BASEDOW, J. The Unidroit Principles of International Commercial Contracts and German Law. GEsselschaft für Rechtsvergleichung. p. 01 apud PESSOA, F. J. B. A consolidação da lex mercatoria como forma de harmonização do direito privado. Dissertação (Mestrado em Direito). Centro de Ciências Jurídicas e Sociais. Pontifícia Universidade Católica do Paraná. Curitiba, 2006. p. 36.
}

Revista Brasileira de Direito Internacional, Curitiba, v.7, n.7, jan./jun.2008 
A codificação, por sua vez, consiste na compilação de regras jurídicas previamente existentes, com o objetivo de fornecer maior segurança àqueles sob sua tutela. Como lembra Pessôa,

O código foi concebido sob uma lógica dedutiva, com axiomas fundantes, delimitando especificamente o espaço para os atos jurídicos, sendo ele auto-suficiente, o elemento único e necessário para regulação de todas as atividades existentes na sociedade e como referencial contrastante entre esta última e o Estado. ${ }^{69}$

O processo de codificação, antes compreendido apenas em âmbito nacional, passa a ser discutido agora também em âmbito regional e, ainda, internacional.

Dentre as tentativas de codificação em âmbito regional, é possível citar o Projeto de Código Civil Europeu, iniciado em 1989 após a publicação da Resolução do parlamento europeu que requereu o início dos estudos preparatórios para a "harmonização" da legislação pertinente às relações privadas.

O Grupo de Estudos pelo Direito Europeu Comum (Groupe d'étude pour le droit européen commun - GEDEC) em um primeiro momento encarregou-se dos estudos e, atualmente, diversos grupos essencialmente privados dão seguimento aos estudos preparatórios para a elaboração do projeto.

Alguns passos importantes já foram dados nesses sentido, em especial a publicação dos Princípios do Direito Europeu dos Contratos (PECL), pela Comissão liderada pelo professor dinamarquês Ole Lando ("Comissão Lando"), bem como as publicações de dois relatórios sobre o Quadro Comum de Referência, o último deles em 2007.

Ainda, dentre as intenções de codificação em âmbito internacional, há o plano do Secretariado do UNIDROIT de promover a "progressiva codificação

\footnotetext{
${ }^{69}$ PESSOA, F. J. B. A consolidação da lex mercatoria como forma de harmonização do direito privado. Dissertação (Mestrado em Direito). Centro de Ciências Jurídicas e Sociais. Pontifícia Universidade Católica do Paraná. Curitiba, 2006. p. 38.
}

Revista Brasileira de Direito Internacional, Curitiba, v.7, n.7, jan./jun.2008 
da legislação sobre o comércio internacional" ${ }^{70} \mathrm{O}$ plano foi apresentado às instituições cujo objetivo principal era o de unificar a legislação internacional sobre o comércio, a saber, UNIDROIT, UNCITRAL, UNCTAD e o Comitê Europeu de Cooperação Legal.

O relatório previa um esforço conjunto dessas instituições e enfatizava a urgência e a necessidade em desenvolver princípios e regras do direito internacional dos contratos que pudessem servir de base para a construção de contratos privados e de convenções internacionais, sem que as partes tivessem a necessidade de recorrer às legislações nacionais.

Neste projeto, em verdade, o UNIDROIT deixava clara sua intenção de elaborar as bases para a edição de um "Código do Direito do Comércio Internacional”, para um legítimo sistema jurídico transnacional.

Ao contrário da CISG, cabe salientar, os PECL e os UPICC não vinculam quaisquer partes ou Estados, mas, como enfatiza Lando, podem se tornar um código civil vinculativo em um piscar de olhos. ${ }^{71}$

Os UPICC e os PECL possuem grandes semelhanças. Os termos e a estrutura utilizada são praticamente idênticos e cerca de dois terços das disposições são idênticas no conteúdo ou na substância. Ambos herdaram muitas das disposições da CISG e, em conjunto com esta, formam um conjunto de regras que influenciou e ainda influencia em muito o comércio internacional.

Há, ainda, planos da UE para desenvolver um Código Civil Europeu que possa ser adotado por todos os países integrantes do bloco. A idéia, entretanto, sofre a oposição de alguns países. A Dinamarca, a Finlândia, a Noruega, a Suécia, a Irlanda e a Grã-Bretanha não possuem um código civil e muitos de seus doutrinadores dizem não necessitar de um. Em outros países que tenham Códigos Civis próprios, ainda se pode encontrar aqueles que

\footnotetext{
70 "In 1971, the secretariat of UNIDROIT presented its idea for the drafting of general principles of international contract law in its report to UNCITRAL on 'progressive codification of the law of international trade'”. BERGER, K. P. The Creeping Codification of the Lex Mercatoria. Hague: Kluwer Law International, 1999. p. 133.

71 "Unlike CISG, the PECL and the Draft European Civil Code are non-binding soft law, but they are framed in such a way that almost without a stroke of the pen they can become a binding civil code". LANDO, O. Culture and Contract Law. European Review of Contract Law. Copenhagen, 2007, Volume 3, p. 2. Disponível em: http://www.referenceglobal.com/doi/pdfplus/10.1515/ERCL.2007.001? cookieSet=1
}

Revista Brasileira de Direito Internacional, Curitiba, v.7, n.7, jan./jun.2008 
resistam à idéia de um Código Civil Europeu, preferindo à atual diversidade existente.

Dentre aqueles que não possuem um código civil propriamente dito, vêse também o desejo desses países de preservar sua cultura jurídica. $\mathrm{Na}$ Inglaterra, por exemplo, as decisões dos Tribunais Superiores continuam sendo uma das mais importantes fontes do direito. As cortes têm de seguir as decisões emanadas das cortes superiores e, cada corte de apelação (exceto a House of Lords), é vinculada às decisões por ela proferidas anteriormente. ${ }^{72} \mathrm{O}$ juiz, assim, tenta extrair regras das decisões proferidas anteriormente.

Os países nórdicos, por sua vez, possuem nos estatutos sua principal fonte do direito há séculos. Apesar de não possuírem um código civil, possuem diversos estatutos que versam sobre as mais diversas matérias. Em verdade, alguns desses estatutos lembram grandes códigos, alguns possuindo mais de 1000 seções.

Apesar das diferenças culturais, estruturais e também de algumas diferenças formais existentes entre os membros da UE, Lando defende que tais motivos não deveriam impedir a UE de adotar um código civil comum, o qual deveria consolidar os princípios comuns a todos os países, presentes nas decisões dos países de common law e nos códigos dos países do continente Europeu.

Observa-se, portanto, que apesar das diferenças e obstáculos que surgem nas tentativas de uniformização e de codificação de uma lei transnacional, persiste a insatisfação dos atores do comércio internacional em relação às legislações nacionais, que não conseguiram e não conseguem acompanhar a evolução das relações internacionais.

Diante da ausência de uma autoridade supranacional, alguns entes privados assumiram a responsabilidade de editar e divulgar regras e princípios comuns às nações de um modo geral, os quais são atualmente utilizados por comerciantes ao redor do globo e, assim, dão os primeiros passos em direção à codificação do direito do comércio internacional.

\footnotetext{
72 LANDO, O. Culture and Contract Law. European Review of Contract Law. Copenhagen, 2007, Volume 3, p. 4. Disponível em: http://www.referenceglobal.com/doi/pdfplus/10.1515/ERCL.2007.001? cookieSet=1
}

Revista Brasileira de Direito Internacional, Curitiba, v.7, n.7, jan./jun.2008 
Dentre as tentativas de codificação até então conhecidas, serão destacados a edição dos Princípios UNIDROIT sobre Contratos Comerciais Internacionais e a publicação dos Princípios do Direito Europeu dos Contratos. Este, por ser a primeira tentativa de codificação em âmbito regional e, aquele, por ser uma das mais importantes tentativas de codificação em âmbito internacional.

\subsection{OS PRINCÍPIOS UNIDROIT SOBRE CONTRATOS COMERCIAIS} INTERNACIONAIS

O International Institute for the Unification of Private Law (UNIDROIT) é uma organização intergovernamental independente, fundada em 1926 como órgão auxiliar da Liga das Nações, re-estabelecido em 1940, após a saída da Itália da Liga das Nações, com base no UNIDROIT Statute ratificado atualmente por 61 países. Seu objetivo principal é o estudo de necessidades e métodos para modernizar e harmonizar legislações comerciais entre Estados e grupos de Estados.

Dentre as publicações emanadas dessa organização, destacam-se os Principles of International Commercial Contracts, que consistem atualmente em 185 artigos distribuídos em capítulos que versam sobre a formação, validade, interpretação, conteúdo, adimplemento, compensação, cessão de créditos, transferência de obrigações e prescrição.

O projeto foi iniciado em 1973, através da criação de um comitê composto pelos Professores Tudor Pospescu, René David e Clive Schmitthoff. Desde o início o grupo procurou elaborar a parte geral de um Código do Direito do Comércio Internacional, pois os contratos em espécie já vinham sendo alvo de processos de unificação promovidos por outras entidades.

O comitê decidiu que as regras e princípios do Direito dos Contratos em geral deveriam ser precedidas de uma parte introdutória, na qual seriam expostos os objetivos de codificação do Direito Internacional dos Contratos e quais seriam as regras e princípios considerados para esses objetivos.

Revista Brasileira de Direito Internacional, Curitiba, v.7, n.7, jan./jun.2008 
$\mathrm{Na}$ década de 80 o primeiro grupo para a efetiva elaboração dos Princípios Gerais dos Contratos foi elaborado, composto por 17 membros permanentes dos mais variados sistemas jurídicos existentes no mundo. Em 31 de fevereiro de 1994 foi publicado o texto final dos UPICC.

Cabe salientar, como lembra Berger, que

(...) o grupo de estudos do UNIDROIT não estava apenas preocupado em consolidar regras comuns e princípios contidos nos sistemas jurídicos domésticos, mas também com a codificação, ..., com o objetivo de criar novas regras e princípios que seriam mais adequadas às necessidades do comércio internacional. ${ }^{73}$

O meio utilizado pelo UNIDROIT para unificar esse conjunto de regras e princípios comuns a vários sistemas jurídicos foi 0 denominado "reafirmação" ${ }^{\text {, }}$, ou seja, ao invés de formular e propor aos diversos países um Tratado Internacional que incorporasse os UPICC, preferiu-se publicar uma consolidação de princípios e regras já existentes, reafirmando-os, evitando assim os longos processos de discussão do projeto com os países potencialmente membros e o processo de internalização do tratado, em geral demasiadamente longo.

Evitou-se, também, a confecção de uma lei-modelo, a qual em geral é negociada e discutida no plano internacional para que possa ser adotada total ou parcialmente para complementar a legislação nacional. Tal modelo traz consigo o risco de que um ou mais Estados não a adotem e, assim, frustram-se as expectativas de uniformização.

Desta forma, o "processo de codificação" ganha eficiência e agilidade, mas também tem seu preço. Para Berger,

\footnotetext{
73 "It is important to note that the UNIDROIT working group was not only concerned with the consolidation of common rules and principles contained in domestic legal systems but also with the codification, i. e. the shaping and modification of solutions to be found in domestic laws, in order to create new rules and principles which are more suited to meet the needs of international trade". BERGER, K. P. The Creeping Codification of the Lex Mercatoria. Hague: Kluwer Law International, 1999. p. 147.

74 "restatement". BERGER, K. P. The Creeping Codification of the Lex Mercatoria. Hague: Kluwer Law International, 1999. p. 152
}

Revista Brasileira de Direito Internacional, Curitiba, v.7, n.7, jan./jun.2008 
Ao consolidar princípios e regras gerais do Direito Internacional dos Contratos, o UNIDROIT parou no meio do caminho entre a criação de regras diretamente aplicáveis ao Direito do Comércio Internacional e a criação de decisões harmônicas através da unificação das regras do Direito Internacional Privado. ${ }^{75}$

Esses princípios oferecem, em suma, um conjunto de regras específicas para a celebração de contratos internacionais, desprovida de influências regionais, elaborada por uma equipe privada e altamente qualificada.

Em seu preâmbulo, dispõe que os princípios ali presentes estabelecem regras gerais que podem ser aplicadas aos contratos internacionais, desde que as partes (i) tenham optado que o contrato seja regido por eles, (ii) tenham acordado que seu contrato seja regido pelos princípios gerais do direito, a lex mercatoria, ou expressões semelhantes ou (iii) não tenham elegido o direito aplicável ao contrato. ${ }^{76}$

Para Berger, é importante salientar que os UPICC constituem uma das possíveis fontes da lex mercatoria, mas com ela não se confundem. Para ele,

os princípios [UNIDROIT] indicam a existência de um sistema jurídico transnacional, e são então uma das possíveis fontes da lex mercatoria, mas não devem com ela ser confundidos. Ë verdade que os princípios não foram adotados pelo Conselho do UNIDROIT com a intenção de ter sua publicação aplicada como a codificação a lex mercatoria pelos árbitros e, assim, consta em seu preâmbulo a palavra "podem" ao invés de "devem" ser aplicadas. A menção das partes a lex mercatoria se refere a um sistema jurídico transnacional que pode ou não estar refletido nos princípios [do UNIDROIT]. ${ }^{77}$

\footnotetext{
75 "by drafting a restatement-like collection of general principles and rules of international contract law, UNIDROIT stopped midway between the creation of directly applicable substantive rules of international contract law and the creation of decisional harmony through the unification of the rules of private international law". BERGER, K. P. The Creeping Codification of the Lex Mercatoria. Hague: Kluwer Law International, 1999. p. 153.

${ }_{77}^{76}$ Principios UNIDROIT sobre los Contratos Comerciales Internacionales, 2004.

77 The principles are na indication of the existence of a transnational legal rule, they are therefore a possible source of the lex mercatoria, but should not be confsed with the lex mercatoria. It is true that the Principles were not adopted by UNIDROIT's Governing Council with the intention to have the publication applied as the codified lex mercatoria by arbitrators. The careful language of the second option ('may' instead of 'have to be' applied) is therefore justified. The parties reference to the lex mercatoria refers to a transnational legal system which may or may not be reflected in the Principles. BERGER, K. P. The Creeping Codification of the Lex Mercatoria. Hague: Kluwer Law International, 1999. p. 179.180.
}

Revista Brasileira de Direito Internacional, Curitiba, v.7, n.7, jan./jun.2008 
Assim, em podendo as partes submeter a interpretação dos contratos por elas celebrados à lex mercatoria e em dispondo o texto dos UPICC que as partes que o tenham feito poderão utilizar os dispositivos ali contidos, é clara a percepção de que, conforme a opinião de Lando, são também os documentos emanados das organizações internacionais fonte da chamada nova lex mercatoria.

\subsection{OS PRINCÍPIOS DO DIREITO EUROPEU DOS CONTRATOS}

As primeiras sugestões para a elaboração de uma consolidação das leis Européias sobre contratos foram dadas em 1960, mas apenas em 1970 o professor dinamarquês Ole Lando sugeriu a confecção de um Restatement do Direito Europeu dos Contratos, ou seja, de uma consolidação de regras e princípios já existentes dentre os países membros da UE, ao invés de aderir à ambiciosa idéia de editar um Código Comercial Uniforme Europeu.

Assim como os UPICC, a Comissão Lando utilizou-se do direito comparado para buscar aquelas regras e princípios comuns aos membros da UE e também de outros países fora do continente.

Os Princípios do Direito Europeu dos Contratos (PECL) foram editados em três momentos: (i) em 1980, uma comissão composta por membros oriundos de diversos países europeus se reuniu, sobre a liderança de Ole Lando, para discutir os princípios específicos para o Direito Contratual Europeu, (ii) em 1992 uma segunda comissão se reuniu, para finalizar os estudos da primeira comissão e prossegui-los em novas áreas, editando em 1996 as partes I e II dos Princípios Contratuais Europeus e (iii) em 1997 reuniuse a terceira e última comissão, que finalizou o estudo das duas primeiras editando em 2001 a terceira parte dos Princípios.

A primeira parte dos trabalhos, publicada em 1995, continha apenas metade das disposições dos UPICC. Eram 59 artigos, divididos em quatro capítulos, que abordavam essencialmente princípios gerais, cumprimento e não cumprimento do contrato, bem como as possíveis soluções em caso de 
descumprimento. Anunciou-se, na ocasião, que os trabalhos não haviam terminado e seriam finalizados pela Comissão Lando.

A versão final dos PECL, preparada pela segunda Comissão, foi publicada pela primeira vez em 1998, estruturada tal como os UPICC. Apresentava 131 artigos, os quais versavam, além das matérias abordadas na primeira edição, sobre formação, validade, interpretação, conteúdo e efeitos dos contratos. Além desses temas, também presentes de maneira geral nos UPICC, os PECL dispõe em seu capítulo 3 sobre a autoridade dos agentes do comércio internacional.

Atualmente, após a publicação da terceira parte dos princípios, observam-se o total de 201 artigos que versam sobre questões relativas ao adimplemento contratual, medidas na ocorrência de inadimplemento, formação do contrato, autoridade de agentes, validade contratual, interpretação, conteúdo, efeitos, cessão de direitos, substituição do devedor, transferência do contrato, compensação, prescrição, ilegalidades, condições e capitalização de interesses.

Assim como o UNIDROIT, a Comissão Lando tinha o objetivo de editar algo mais do que uma simples coleção de regras e princípios gerais, mas de apresentar um "Sistema do Direito Europeu dos Contratos",78 e, não por outro motivo, atingiu resultados muito próximos àqueles atingidos pelos UPICC, com algumas diferenças terminológicas, mas poucas diferenças substanciais.

O projeto foi de iniciativa privada, não recebendo qualquer incentivo ou chancela governamental, mas acabou por uniformizar legislações e costumes presentes o direito europeu, bem como por aproximar os regimes jurídicos da common law e da civil law, ao menos no que tange o Direito dos Contratos. Nas palavras de Lando,

Em 1980 a Comissão de Direito Europeu dos Contratos iniciou seus trabalhos. Atribuiu a si mesma a tarefa de consolidar princípios gerais europeus para um Sistema Comum do Direito dos Contratos. A Comissão é uma associação privada independente de operadores do direito oriundos de todos os países membros da União Européia.

${ }^{78}$ BERGER, K. P. The Creeping Codification of the Lex Mercatoria. Hague: Kluwer Law International, 1999. p. 201.

Revista Brasileira de Direito Internacional, Curitiba, v.7, n.7, jan./jun.2008 
Iniciou dedicando-se ao Direito dos Contratos, pois o instrumento mais importante ao business management e ao planejamento da economia de mercado são os contratos privados. A comissão iniciou seus trabalhos analisando os efeitos e o cumprimento dos contratos, também lidando com o descumprimento e em especial com as lacunas contratuais. $^{79}$

A publicação dos PECL, então, representou o primeiro passo em direção ao desenvolvimento de uma rede de princípios comuns do Direito Europeu Privado, e o primeiro passo em direção à confecção de um Código Europeu dos Contratos.

Em suma, os PECL possuem quatro funções essenciais. A primeira delas reside na intenção de prover a base para a codificação do Direito Europeu dos Contratos. Apesar de alguns se referirem aos PECL como "código", este conjunto de regras é visto apenas como uma "sombra" de um futuro próximo. Já a segunda característica reside no fato de os PECL proverem um corpo normativo que servirá de base para evitar conflitos futuros em relação a harmonização do Direito dos Contratos. A terceira, por sua vez, estabelece que os PECL devem prover as linhas gerais para a interpretação da lei harmonizada fora da UE. A quarta e última se refere ao objetivo da Comissão Lando de contribuir para a formação de um ius commune Europeu, como a lex mercatoria, limitado aos membros da UE. ${ }^{80}$

Quanto a sua aplicação, observa-se em seu Capitulo I que os princípios ali descritos têm por objetivo serem aplicados como regras gerais de direito dos contratos na União Européia, desde que (i) as partes o tenham incorporado ao contrato ou a eles o submetam, (ii) quando tenham submetido o contrato ao regime dos princípios gerais do direito, da lex mercatoria, ou de

\footnotetext{
79 "In 1980 the Commission on European Contract Law began its work. It set itself the task of formulating general European principles for a common system of contract law. The Commission is an independent private association of legal scholars from all Member States of the European Community. It has begun by devoting itself to the law of contract, because the most important instrument of business management and planning in a market economy is the private contract. The Commission began by examining the effects and the performance of contracts. It also dealt with impairment of performance and especially breaches of contract". LANDO, O. The Rules of European Contract Law. Study of the systems of private law in the EU with regard to discrimination and the creation of a European Civil Code. European Parliament, Directorate General for Research, Working Paper, Legal Affairs Series, 1999., Chapter III, p.128.

${ }^{80}$ BERGER, K. P. The Creeping Codification of the Lex Mercatoria. Hague: Kluwer Law International, 1999. p. 198.
}

Revista Brasileira de Direito Internacional, Curitiba, v.7, n.7, jan./jun.2008 
expressões similares ou, ainda, (iii) quando não tenham optado por qualquer sistema legal pelo qual se deve reger o contrato. ${ }^{81}$

Assim como os UPICC, portanto, em podendo as partes submeter à interpretação dos contratos por elas celebrados à lex mercatoria e, em dispondo o texto dos PECL que as partes que o tenham feito poderão utilizar os dispositivos ali contidos, constitui-se em fonte da chamada nova lex mercatoria.

A grande diferença entre os conjuntos de princípios apresentados, os UPICC e os PECL reside, em grande parte, na possibilidade de aplicação das disposições dos PECL não apenas a contratos internacionais, mas também a contratos nacionais no âmbito da comunidade européia, bastando que as partes optem por tal sistema de regras no corpo do contrato ou, ainda, que o contrato seja omisso em relação à lei aplicável.

No mais, ambos os conjuntos de princípios cobrem a maioria dos quesitos relacionados aos contratos, com uma linguagem clara e com destinatários definidos. Não possuem uma função definida e, por isso, devem servir como modelo à interpretação de leis internacionais ou nacionais referentes a contratos, não sendo vinculantes à quaisquer partes. Clara, portanto, a autonomia da vontade das partes em escolher a lei aplicável ao contrato, definida já no preâmbulo dos dois dispositivos.

\subsection{RUMO À CODIFICAÇÃO DA LEX MERCATORIA}

A evolução de um sistema autônomo do comércio internacional, fundado em princípios universais e em padrões de conduta observados no diaa-dia da comunidade internacional, "seria um dos mais importantes desenvolvimentos da ciência jurídica do nosso tempo"82 Com essas palavras, Clive Schmitthoff abriu o London Colloquium on the New Sources of the Law of International Trade, realizado no King's College, em Londres, em 1962.

\footnotetext{
${ }^{81}$ Principios de Derecho Europeo de Los Contratos, 2000.

82 SCHMITTHOFF, C. apud .BERGER, K. P. The New Law Merrchant and the Global Market Place - A 21st Century View of Transnational Commercial Law. Disponível em: <http://tldb.unikoeln.de>. Acesso em 05/08/2008
}

Revista Brasileira de Direito Internacional, Curitiba, v.7, n.7, jan./jun.2008 
A idéia de se constituir um sistema jurídico do comércio internacional é, então, antiga, mas mesmo após quarenta anos de discussão sobre o tema, a doutrina que defende a existência de uma lei transnacional dos contratos está longe de visualizar a solução dos problemas encontrados.

Em geral, o ceticismo com que se observa a lex mercatoria, em não lhe atribuir a certeza e provabilidade das legislações nacionais, é um dos maiores empecilhos à evolução das discussões.

Por contraste, a edição dos UPICC e dos PECL vem na direção oposta, consolidando regras e princípios comumente utilizados no comércio internacional e presentes nos sistemas jurídicos dos mais diversos países. Alguns autores, como lembra Berger, consideram esses dispositivos como "autêntica expressão do que é geralmente conhecido como lex mercatoria"

Para Berger, ainda, a edição e publicação desses dispositivos consiste em uma mudança dramática nas discussões em torno da lex mercatoria, pois

[os Princípios do UNIDROIT e os Princípios do Direito Europeu dos Contratos] ratificam o fenômeno da creeping codification do direito transnacional. Isto reflete uma mudança de paradigma no Direito do Comércio Internacional, na produção de regras saindo das tradicionais organizações internacionais para organizações "privadas". A produção do Direito Comercial Transnacional está "privatizada". Nesse contexto transnacional, entretanto, "codificação" não significa produção, mas "reprodução" de leis e/ou regras. Grupos de Estudo privados, mesmo quando agem sob comando de organizações internacionais, não produzem a lex mercatoria. A nova lex mercatoria é criada pelas partes das relações comerciais internacionais e pelos tribunais arbitrais. ${ }^{84}$

\footnotetext{
${ }^{83}$ BONNEL, M. J. apud BERGER, K. P. The New Law Merrchant and the Global Market Place A 21st Century View of Transnational Commercial Law. Disponível em: <http://tldb.unikoeln.de>. Acesso em 05/08/2008

84 "They stand for the phenomenon of the 'creeping codification of transnational law'. This reflects a change of paradigm in international commercial efforts. The making of transnational commercial law is 'privatized'. In this transnational context, however, 'codification' does not mean production but 'reproduction' of law. Privat Working Groups, even when they are acting under the umbrella of a formulating agency, are not the lawmakers of the lex mercatoria. The new lex mercatoria is created by the parties to international commercial transactions and their arbitral tribunals." BERGER, K. P. The New Law Merrchant and the Global Market Place - A 21st Century View of Transnational Commercial Law. Disponível em: <http://tldb.uni-koeln.de>. Acesso em 05/08/2008.
}

Revista Brasileira de Direito Internacional, Curitiba, v.7, n.7, jan./jun.2008 
A noção de creeping codification possui, então, duas características principais. A primeira delas é a de que há uma reversão no processo de produção legal tradicional, sendo as regras produzidas "de baixo" e não mais pelos meios tradicionais conhecidos. São agora produzidas pela prática jurídica ou por acadêmicos, por vezes sob tutela de organizações internacionais como - UNIDROIT. A segunda, por sua vez, refere-se ao desenvolvimento gradual ao longo do tempo, ou seja, a creeping codification traduz-se em um processo lento, além de informal e privado. Para Berger, ainda, esta segunda característica deriva basicamente do fato de ser a lei transnacional uma lei viva, em constante processo de atualização.

Cabe salientar, não se afirma que atualmente os UPICC e os PECL sejam "códigos" do direito do comércio internacional. O que se constata é que há, hoje, a produção do direito por entidades totalmente desvinculadas do poder estatal e destinadas a um grupo específico de pessoas. Essas publicações, apesar de não constituírem "códigos" em si, fornecem a base e os primeiros passos em direção a essa "codificação".

Salienta-se, ainda, que o termo "codificação" não é aconselhável, pois carrega em si vinculo estreito à soberania estatal e ao processo legislativo. Assim, prudente a escolha de Berger, ao denominar esse processo de "creeping codification" do direito do comércio internacional.

Revista Brasileira de Direito Internacional, Curitiba, v.7, n.7, jan./jun.2008 


\section{CONSIDERAÇÕES FINAIS}

O comércio internacional há séculos não é regulado apenas pelas leis regionais, seja a lex fori ou a lex loci arbitri, mas também por usos e costumes estabelecidos pelos próprios comerciantes. A esse conjunto de usos e costumes, bem como aos contratos-tipos e às decisões arbitrais fundamentadas em princípios gerais do direito que não estão vinculadas a qualquer sistema jurídico nacional atribui-se o nome de lex mercatoria.

$\mathrm{O}$ advento do Estado Moderno assimilou às codificações nacionais os princípios que até então regulavam o comércio internacional, mas logo o desenvolvimento do comércio, acelerado principalmente após a Segunda Guerra Mundial, tornou obsoletas e inúteis as disposições Estatais e, novamente, os usos e costumes dos comerciantes internacionais construíram um conjunto de regras e princípios que poderiam atender às suas necessidades, desvinculado de qualquer sistema jurídico nacional. A esse novo movimento, Goldman denominou "nova lex mercatoria".

Posteriormente, a doutrina divergiu e ainda diverge quanto a alguns pontos da definição dessa "nova lex mercatoria", em especial quanto a sua natureza jurídica. Os críticos da teoria formulada por Goldman, como Lagarde e Antoine Kassis, não a consideravam como um sistema jurídico autônomo, baseados no fato de que não possuía previsibilidade, consistência e não eram passíveis de serem aplicadas aos casos concretos, salvo como espécie de princípios gerais do direito, para cobrir as lacunas do sistema jurídico Estatal.

$\mathrm{Na}$ década de 90 , entretanto, a comunidade jurídica internacional observou a consolidação de inúmeros princípios do direito contratual, comuns a diversos países e já utilizados pelos comerciantes internacionais. Tal consolidação se deu através da edição dos Princípios UNIDROIT sobre os Contratos Comerciais Internacionais e dos Princípios do Direito Europeu dos Contratos.

Tal consolidação se deu através de instituições privadas, desvinculadas de relação com quaisquer estados e, em princípio, sem o objetivo de auferir lucros, em forma muito semelhante à dos códigos 
contemporâneos. Apesar de ainda não ratificadas por qualquer país e de não terem sido elaboradas por qualquer autoridade estatal ou interestatal, tais disposições vêm sendo utilizadas com freqüência por comerciantes internacionais e por árbitros em solução de conflitos internacionais.

Essas publicações, ainda, expressam claramente que, uma vez elegidas pelas partes para regular a relação contratual, ou ainda em tendo as partes elegido a lex mercatoria para regular a relação contratual, seus dispositivos tornar-se-ão aplicáveis ao contrato e poderão ser utilizados por árbitros ou mesmo por juízes nacionais para solucionar eventuais conflitos.

Considerando, então, que a codificação desses princípios representa um sistema de regras estabelecido com a intenção de agregar princípios comuns a diferentes sistemas jurídicos nacionais e, ainda, adaptados às necessidades especiais dos Contratos Internacionais, ambos consolidam-se como a uma espécie de codificação anômala, ou creeping codification, como denomina Berger, da chamada "nova lex mercatoria".

Agora os princípios existentes podem ser levados a cortes nacionais, internacionais ou ainda tribunais arbitrais, e podem ser referidos com numero da página e do artigo que remete ao princípio que fundamentará a decisão. A teoria da lex mercatoria trilha, então, seu caminho rumo à codificação e passa, então, a ser considerada um conjunto de regras previsíveis e consistente, descartando então as críticas até então existentes quanto às suas fontes e características e quanto à ausência de um meio eficaz de coerção.

Todos esses fenômenos podem, em geral, ser atribuídos às transformações que ocorreram e que vem ocorrendo na economia global, tais como o fim da guerra fria, o progresso da integração européia, o estreitamento das relações comerciais entre países, o desenvolvimento dos recursos tecnológicos e demais fatores atualmente reunidos sob a denominação comum de "globalização", que mudaram drasticamente o cenário do comércio internacional.

Como conseqüência desse novo cenário, vê-se a prevalência do princípio da autonomia da vontade das partes ao celebrar contratos, a percepção de que em muitos casos as leis domésticas não são aplicáveis aos 
conflitos comerciais modernos, a ampla utilização das disposições da CISG e de outros instrumentos uniformes no âmbito do direito dos contratos, a maior utilização do direito comparado como ferramenta de estudo, dentre outras.

Esse novo cenário foi e é altamente propício à discussão quanto à codificação do direito dos contratos e, crêem os mais ambiciosos, do próprio direito civil. Não obstante, conforme se observou, os UPICC e os PECL não constituírem "códigos" em si, não é possível negar sua grande contribuição à uniformização do direito dos contratos internacional.

\section{REFERÊNCIAS}

AMARAL, Antônio Carlos Rodrigues do. Direito do Comércio Internacional: aspectos fundamentais. São Paulo: Aduaneiras, 2004.

BADDACK, Frank. Lex Mercatoria: Scope and Application of the Law Merchant in Arbitration. Tese (LL.M., mode III) - Faculty of Law, University of the Western Cape, Cape Town, South Africa, 2005. Disponível em: < http://etd.uwc.ac.za/usrfiles/modules/ etd/docs/etd_init_3939_1174049802.pdf>. Acesso em 30/07/2008.

BERGER, Klaus Peter. The Creeping Codification of the Lex Mercatoria. Hague: Kluwer Law International, 1999.

. The New Law Merchant and the Global Market Place - A 21st Century View of Transnational Commercial Law. Disponível em: <http://tldb.unikoeln.de>. Acesso em 05/08/2008.

BILLS OF EXCHANGE ACT. Disponível em: http://www.opsi.gov.uk/RevisedStatutes/

Acts/ukpga/1882/cukpga_18820061_en_1. Acesso em 05/08/2008.

COMISIÓN DE DERECHO EUROPEO DE LOS CONTRATOS. Principios de Derecho Europeo de Los Contratos: Partes I y II (revisadas), 2000. Disponível em: http://biblioteca.uam.es/derecho/documentos/docencia/civil/PECL1-2.pdf. Acesso em 29/06/2008.

DAL RI JUNIOR, Arno. História do Direito Internacional: Comércio e moeda; Cidadania e Nacionalidade. Florianópolis: Fundação Boiteux, 2004.

FIORATI, Jete J. A lex mercatoria como ordenamento jurídico autônomo e os Estados em desenvolvimento. Revista de Informação Legislativa. Brasília, ano 41, n. 164, p. 17-30. out-dez 2004. 
GOLDMAN, B. Nouvelles Réflexions sur la Lex Mercatoria. Festschrift Pierre Lalive, Basel. Frankfurt: a.M., 1993. p. 241-255. Disponível em: <http://tldb.unikoeln.de>. Acesso em: 05/08/2008.

GOLDSTAIJN, A. The new law merchant reconsidered. Festschrift Schmitthoff. Frankfurt, p. 171-185, 1973. Disponível em: <http://tldb.uni-koeln.de>. Acesso em 15/06/2008.

HEIGHET, Keith. The enigma of the lex mercatoria, In: CARBONNEAU, Thomas E. (ed.). Lex mercatoria and arbitration: a discussion of the new law merchant. New York: Juris Publications, 1998. P. 98-108.

HUCK, Hermes Marcelo. Sentença estrangeira e lex mercatoria: horizontes e fronteiras. São Paulo: Saraiva, 1994.

LAGARDE, Paul. Approche critique de la lex mercatoria. In: FOUCHARD; KAHN, Philippe; LYON-CAEN, Antoine (ed.). Le droit des relations économiques internacionales: Etudes offerts à Berthold Goldman. Paris: litec, p. 130-145, 1982.

LANDO, Ole. The law applicable to the merits of the dispute. In: SARCEVIC, P. (ed.). Essays on International Commercial Arbitration. Boston, London: 1991. P. 130-159. Disponível em: <http://tldb.uni-koeln.de>. Acesso em 05/08/2008.

Culture and Contract Law. European Review of Contract Law. Copenhagen, 2007, Volume 3, p. 1-20. Disponível em: http://www.referenceglobal.com/doi/pdfplus/10.1515/ERCL.2007.001? cookieSet=1. Acesso em 05/07/2008.

The Rules of European Contract Law. Study of the systems of private law in the EU with regard to discrimination and the creation of a European Civil Code. European Parliament, Directorate General for Research, Working Paper, Legal Affairs Series, 1999., Chapter III, p.127-136. Disponível em: http://www.cisg.law.pace.edu/cisg/biblio/lando2.html. Acesso em 10/06/2008.

MOLINEAUX, Charles. Moving toward a lex mercatoria: a lex constructionis. International Arbitration, n. 1, p. 55-66, 1997. Disponível em: <http://tldb.unikoeln.de>. Acesso em 15/06/2008.

OECD GUIDELINES FOR MULTINATIONAL ENTERPRISES. Disponível em: http://www.oecd.org/daf/investment/guidelines. Acesso em 05/08/2008.

ORDINANCE OF THE STAPLES. Disponível em <http://home.freeuk.net/donaitken/ast/e3b.html\#74. Acesso em 05/08/2008.

PEREIRA, Luis C. R. Costume Internacional: Gênese do Direito Internacional. Rio de Janeiro: Renovar, 2002. 
PESSÔA, Fernando J. B. A consolidação da lex mercatoria como forma de harmonização do direito privado. Dissertação (Mestrado em Direito). Centro de Ciências Jurídicas e Sociais. Pontifícia Universidade Católica do Paraná. Curitiba, 2006.

RODRIGUEZ, Ana Mercedes López. Lex mercatoria. Retsvidenskabeligt Tidsskrift. 2002. Disponível em: http://www.rettid.dk/artikler/20020046.pdf. Acesso em: 01/07/2008.

RULES OF OLERON, THE. Disponível em: http://www.admiraltylawguide.com/ documents/oleron.html. Acesso em: 05/08/2008.

SALES OF GOODS ACT. Disponível em: http://www.paclii.org/vu/legis/vuuk_act/soga1893128. Acesso em 05/0802008.

STRENGER, Irineu. Direito do Comércio Internacional e Lex Mercatoria. São Paulo: LTr, 1996.

SWEET, Alec Stone. The new Lex Mercatoria and transnational governance. Journal of European Public Policy. Londres, 05/08/2006. P. 627-646. Disponível em: http://works.bepress.com/alec_stone_sweet/4/

SYMEONIDES, Symeon C. Party Autonomy and Private-Law Making in Private International Law: The Lex Mercatoria that Isn't. 2006. Disponível em: <http://ssrn.com/abstract=946007>. Acesso em 12/07/2008.

TEUBNER, Gunther. Global Bukowina: Legal Pluralism in the World-Society. Global Law Without a State. Burlington: Ashgate, 2003. Disponível em: http://ssrn.com/ abstract=896478. Acesso em: 05/06/2008

UNIDROIT. Principios UNIDROIT sobre los Contratos Comerciales Internacionales, $2004 . \quad$ Disponível em: http://www.unidroit.org/english/principles/contracts/main.htm. Acesso em: 28/06/2008. 